\title{
EL DERECHO AL ASILO DE MENORES NO ACOMPAÑADOS: UNA PROPUESTA DE REGULACIÓN MÁS SEGURA
}

\author{
LUCÍA ALONSO SANZ
}


1. INTRODUCCIÓN. 2. FUENTES: 2.1. La relevancia de las normas supranacionales: A) Derecho de asilo. B) Protección del menor. C) Disposiciones específicas. 2.2. Derecho interno: A) La Constitución y el Derecho Internacional. B) La doble dimensión de la protección constitucional del menor. C) Desarrollo infraconstitucional relevante 3. ALGUNOS PRINCIPIOS: 3.1. Supremacía del interés del menor. 3.2. No discriminación. 3.3. Participación o derecho a ser oído. 3.4. Responsabilidad e intervención activa de los poderes públicos en la realización efectiva de los derechos del menor. 4. PROCEDIMIENTO: TENUE APLICACIÓN DE LOS PRINCIPIOS GENERALES: 4.1. Acceso al procedimiento de asilo: A) (Falta de) acceso. B) Identificación. C) Prohibición de detención/ retención. 4.2. Representación y asistencia jurídica. 4.3. Audiencia del menor. 4.4. Valoración y resolución de la solicitud de asilo. 5. CONCLUSIONES. 


\title{
EL DERECHO AL ASILO DE MENORES NO ACOMPANADOS: UNA PROPUESTA DE REGULACIÓN MÁS SEGURA
}

POR

\author{
LUCÍA ALONSO SANZ \\ Becaria de investigación \\ Universidad Complutense de Madrid
}

\section{INTRODUCCIÓN}

En los últimos años ha aumentado significativamente el número de extranjeros menores no acompañados que entran a España de manera clandestina ${ }^{1}$. La ausencia de cuidado efectivo de un adulto que, por ley o costumbre, sea responsable de ellos ${ }^{2}$ sitúa a estos menores en situación legal de desamparo (art. 172 CC). Camuflados en estas oleadas migratorias, existen potenciales solicitantes de asilo que nunca llegan a disfrutar de la protección que legal y constitucionalmente les corresponde.

\footnotetext{
1 Según el Informe La Infancia en cifras, elaborado por el Instituto de Infancia y Mundo Urbano para el Ministerio de Trabajo y Asuntos Sociales (octubre de 2006), en el año 2004, 9.117 menores extranjeros no acompañados llegaron a nuestro país. Informe http://www.mtas.es/sgas/FamiliaInfanclinfancialAcuerdosConvenios/InfanciaCifras.pdf, citado en DíAZ CrEGO, M.: "Minoría de edad y derechos fundamentales", en Escobar RocA, G. (dir.): Derechos sociales y tutela antidiscriminatoria, Aranzadi - Defensor del Pueblo, próxima publicación.

2 Esta es la nota definitoria del colectivo de «menores no acompañados» según la Resolución de la Unión Europea 97/C/221/03, de 19 de julio de 1997, sobre Menores No Acompañados.
} 
Las solicitudes de asilo presentadas por menores no acompañados en España son escasísimas. Podría pensarse que estamos ante un fenómeno marginal, cuya regulación habría de asimilarse plenamente a la genérica del procedimiento de asilo, como en cierta medida ocurre en la actualidad, asumiendo que la práctica inexistencia de supuestos de hecho no exigiría la regulación específica del fenómeno. Paradójicamente, esta aparente falta de problema es el principal indicio de que tal problema existe. Me explicaré. ¿̇ qué se debe la limitadísima cifra de solicitudes de asilo de menores no acompañados? ¿Por qué, en cambio, existen peticiones de asilo de adultos provenientes de los mismos países que los menores que no solicitan dicha protección?3

El principal problema en materia de solicitantes de asilo menores no acompañados radica en la falta de detección de los casos, que impide de hecho que este colectivo acceda al procedimiento. Las razones de este problema son diversas, pero es evidente que en gran medida el dato de que los menores no demanden la protección que posiblemente merecen se debe a su total desinformación sobre el derecho de asilo. Además, los que llegan a solicitarlo, se enfrentan a un largo, duro y complejo procedimiento administrativo (que puede terminar en contencioso) que no cumple con las especificidades procesales que requeriría la acusada vulnerabilidad de este colectivo, fruto de la intersección entre minoría de edad y situación de asilo. Es necesario que la regulación de dicho procedimiento sea coherente con la necesidad de protección especial del menor, fundada en su falta de desarrollo integral, vulnerabilidad y dependencia ${ }^{4}$.

El presente trabajo constará de tres partes. En primer lugar, se identificarán los preceptos de Derecho internacional, europeo e interno que, bien por regular la protección especial del menor, bien por atender a la condición de solicitante de asilo o de extranjero, deberían aplicarse en el procedimiento de asilo de menores no acompañados. En una segunda parte se tratarán de analizar los principios generales del Derecho que se infieren de las fuentes mencionadas en la primera parte, valorando especialmente las implicaciones de los mismos en el tema que nos ocupa. Finalmente, se examinarán ciertos aspectos del procedimiento de asilo de menores que puedan requerir, a la luz de las regulaciones y principios analizados, un tratamiento específico, determinando si tal trata-

3 Se reciben en España, en efecto, solicitudes de asilo de personas mayores de edad provenientes de Marruecos y de otros puntos de África subsahariana, principales lugares de origen de los menores no acompañados que llegan a España. Cfr. estadísticas de la Oficina de Asilo y Refugio: http://www.intermigra.info/extranjeria/archivos/revista/Mayo2006.pdf

${ }^{4}$ COMITÉ EJECUTIVO DEL ACNUR, Política del ACNUR sobre los Niños Refugiados, E/SCP/82, de 6 de agosto de 1993. Este documento puede consultarse en: www.acnur.org/biblioteca/pdf/1682/pdf 
miento se refleja en la ley y/o en la práctica administrativa y, en caso negativo, si sería conveniente regularlo.

Desde ahora adelanto, por una parte, que tal coherencia normativa entre principios generales y regulación específica del problema no existe y, por otra, que es necesario dotar de una mayor seguridad jurídica a la regulación del procedimiento de asilo de menores 5 .

Teniendo en cuenta la naturaleza esencialmente procesal del derecho de asilo $^{6}$, las especificidades del procedimiento adquieren una relevancia extraordinaria para su efectivo ejercicio, e inciden notablemente en que la protección brindada por el mismo sea real y efectiva, tal y como el Tribunal Europeo de Derechos Humanos pide que se garanticen los derechos ${ }^{7}$.

\section{FUENTES}

La determinación de las fuentes reguladoras del procedimiento de asilo de menores no acompañados en España exige, en primer lugar, indagar en la normativa aplicable a cada una de las condiciones definitorias del colectivo que nos ocupa, a saber: situación de asilo y menor edad. Confluyen en estas personas dos procesos paralelos de lo que Bobbio denominó «especificación» de derechos, que no es más que «el paso gradual, pero siempre muy acentuado, de una ulterior determinación de los sujetos titulares de derechos» ${ }^{8}$. En virtud de

5 Mi experiencia en el apoyo legal a solicitantes de asilo en la Comisión Española de Ayuda al Refugiado, así como los problemas que allí he presenciado, me han proporcionado una perspectiva práctica en materia de asilo que, sin duda, ha ayudado notablemente a enfocar el tema de este trabajo.

${ }^{6}$ Cfr. Santolaya Machetti, P. El derecho de asilo en la Constitución española, Lex Nova, Madrid, 2001, p. 53.

${ }^{7}$ A modo de ejemplo, ver STEDH de 11 de noviembre de 2004, asunto Moreno Gómez contra España, en el que el Tribunal Europeo «reitera que la Convención pretende proteger derechos efectivos, no ilusorios», párr. 61.

${ }^{8}$ El autor alude a este fenómeno al explicar la evolución de la doctrina sobre los derechos del hombre. Según él, después de los procesos de positivación, generalización e internacionalización de los derechos humanos, se ha producido un proceso de «especificación», en el marco de una cada vez mayor adaptación y adecuación de la teoría de los derechos a la compleja realidad social. Así, Bobbio realiza una analogía entre el desarrollo y concreción de ciertos derechos abstractos, tales como la libertad, en posteriores derechos concretos, como libertad de conciencia, de expresión, de reunión o de asociación, y la progresiva determinación del sujeto abstracto "persona» en ulteriores especificaciones, tales como, y en primer lugar cronológicamente, "ciudadano", y posteriormente otras categorías basadas en el género, en la edad o en la excepcionalidad o no de la situación en la que el titular se halle. BobBIO, N.: El tiempo de los derechos, Sistema, Madrid, 1991, p. 109.

(C) UNED. Revista de Derecho Político

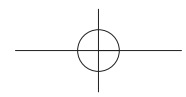


su vulnerabilidad interseccional, este grupo se convierte en centro de imputación de los derechos «específicos» reconocidos, por una parte, a los solicitantes de asilo y por otra, a los menores de edad. Parafraseando al Alto Comisionado de las Naciones Unidas para los Refugiados (en adelante, ACNUR), los niños refugiados «comparten ciertos derechos universales con todas las demás personas, tienen derechos adicionales en su calidad de niños y derechos particulares por ser refugiados»"

La regulación del derecho de asilo y su procedimiento ordinario y el régimen jurídico de protección del menor se caracterizan en nuestro ordenamiento jurídico por un alto grado de influencia y dependencia del Derecho Internacional y, en los últimos años, también del emanado de la Unión Europea.

\subsection{La relevancia de las normas supranacionales}

A) Derecho de asilo

Desde que el legislador español restringió su discrecionalidad en materia de asilo y asimiló esta figura a la del refugio internacional, nuestro marco legal en materia de asilo ha sido un fiel reflejo, si bien ampliado, de la Convención de Ginebra sobre el Estatuto de los Refugiados, de 1951, y su Protocolo (Nueva York, 1967), pilares del llamado Derecho Internacional de los Refugiados. No obstante, estas fuentes juegan un importante pero limitado papel a efectos de nuestro tema ${ }^{10}$, ya que no contemplan cuestiones procesales.

Por otra parte, la regulación española del derecho de asilo se está viendo progresivamente condicionada por la normativa emitida al efecto por la Unión Europea, en el marco del proceso de armonización en materia de inmigración y asilo, que ha supuesto el establecimiento de unos mínimos por parte de la Unión que sus miembros deben respetar. De especial relevancia para el tema objeto de estudio es la Directiva sobre el Procedimiento de Asilo ${ }^{11}$, cuyo art. 17 recoge las especificidades aplicables a los menores inmersos en este procedimiento.

9 COMITÉ EJECUTIVO DEL ACNUR, Política del ACNUR sobre los niños refugiados, E/SCP/82, de 6 de agosto de 1993, párr. 16. http://www.acnur.org/biblioteca/pdf/1682.pdf

${ }^{10}$ Goodwin - Gill, G. S. : «Protecting the Human Rights of Refugee Children: Some Legal and Institutional Possibilities, en Doek, J. , Van LoON, H. and VlaArdingerbroek, P. : "Children on the Move. How to Implement Their Right to Family Life», Martinus Nijhoff Publishers, La Haya, Holanda, 1996, pp. 97 - 108, p.97.

11 Directiva 2005/85/CE del Consejo, de 1 de diciembre de 2005 (DOCE L 326 de 13.12.2005, p. 13/34). 
El Tratado de Lisboa inaugura una nueva etapa que supone la progresiva sustitución de las vigentes medidas de armonización por una regulación común de ciertos aspectos relacionados con el asilo, incluido el procedimiento ${ }^{12}$. Esto significa que en un futuro próximo las solicitudes de asilo deberán instruirse conforme a un procedimiento común para todos los estados de la Unión, y será entonces tal procedimiento el que deberá contener especificidades procesales sensibles con las necesidades de los menores no acompañados.

Además, el derecho a solicitar asilo aparece reconocido en el art. 18 de la Carta de Derechos Fundamentales de la Unión Europea ${ }^{13}$, así como el clásico principio de non refoulement (art. 19).

Fuera de la UE, el art. 3 del Convenio Europeo de Derechos Humanos, que prohíbe las penas y tratos crueles, inhumanos y degradantes, supone, tal y como ha sido interpretado por el Tribunal Europeo de Derechos Humanos, la prohibición de expulsar a una persona a un país donde pueda sufrir ese tipo de maltrato ${ }^{14}$, y constituye, en la práctica, otra fuente de protección del derecho de asilo en Europa ${ }^{15}$.

\section{B) La protección del menor}

La parca regulación constitucional en materia de protección del menor ha quedado compensada por un amplio desarrollo legislativo, tanto estatal como autonómico, profundamente influido por la normativa internacional en la materia, y muy especialmente por la que se considera su piedra angular: la Convención de Naciones Unidas sobre Derechos del Niño (en adelante, «la Con-

${ }^{12}$ El artículo 78.2 del Tratado de Funcionamiento de la Unión Europea prevé la adopción de medidas conducentes a «procedimientos comunes para conceder o retirar el estatuto uniforme de asilo o de protección subsidiaria».

13 El nuevo Tratado de Lisboa reconoce a la Carta el mismo valor jurídico que los Tratados (art. 6.1 TUE tras la modificación de Lisboa).

${ }^{14}$ Un estudio sobre el significado y alcance otorgado por el Tribunal Europeo de Derechos Humanos al artículo 3 del Convenio y su virtualidad para amparar el principio de non refoulement, puede encontrarse en: SALADO OSUNA, A.: «La tortura y otros tratos prohibidos por el Convenio (art. 3 CEDH)», en García Roca, J y Santolaya Machetti, P. (Coords.): La Europa de los derechos: el Convenio Europeo de derechos humanos, Centro de Estudios Políticos y Constitucionales, Madrid, 2005, pp. 97-131.

${ }^{15}$ El sistema de protección bifronte vigente en Europa (UE - Consejo de Europa), de asilo en particular y de derechos humanos en general, alcanzará previsiblemente una mayor armonía y coordinación cuando la Unión Europea como tal, se adhiera al Convenio Europeo de Derechos Humanos, en cumplimiento del artículo 6.2 de la nueva versión del TUE, fruto de la modificación realizada en Lisboa. 
vención»), de 1989. La particular vis expansiva de este instrumento se debe a los tres principios fundamentales que constituyen el esqueleto de todo su articulado, a saber, interés superior del menor, no discriminación y derecho de participación. Más adelante se abordará el significado, alcance e implicaciones de dichos principios, cuya confluencia constituye el nudo gordiano de los regímenes modernos de protección del menor.

La honda acogida interna, tanto a nivel legislativo ${ }^{16}$ como jurisprudencial $^{17}$, del Derecho internacional, ha producido una considerable armonía entre ambos ordenamientos en este punto, armonía extensiva también al Derecho comparado occidental, y en parte universal, lo que se manifiesta en el gran consenso existente en torno a la Convención ${ }^{18}$.

Esta inusitada unanimidad se debe, en gran parte, a determinada precomprensión del menor vigente en las últimas décadas ${ }^{19}$, que subyace a las diversas normativas y a la interpretación de las mismas y de la que son fiel reflejo los tres

16 Las dos leyes principales en materia de protección de la infancia, a saber, Ley Orgánica 1/1996, de Protección Jurídica del Menor y Ley Orgánica 5/2000, reguladora de la Responsabilidad Penal de los Menores, reconocen expresamente a todo menor los derechos recogidos en la Convención (art. 3 y 1, respectivamente).

17 En la STC 141/2000, de 29 de mayo, FJ 5, el TC incluye a la Convención en el que denomina «estatuto jurídico indisponible de los menores de edad dentro del territorio nacional», integrado también por la Resolución del Parlamento Europeo relativa a la Carta Europea sobre Derechos del Niño (Resolución A 3-0172/92 de 8 de julio) y la Ley de Protección Jurídica del Menor.

18 Es el tratado internacional más ampliamente ratificado de la historia. Actualmente cuenta con 192 Estados parte, es decir, todos los Estados miembros de la comunidad internacional excepto Somalia y Estados Unidos. Este amplio consenso se ha vinculado con el llamado «talón de Aquiles» de la Convención: el significativo número de reservas formuladas por los Estados parte. Sin embargo, la libertad de los Estados para oponer reservas no es ilimitada, y la eficacia y validez de las mismas puede ser evaluada por los órganos convencionales que vigilan el cumplimiento de los tratados que, eventualmente, determinarán también las consecuencias derivadas de la invalidez de las reservas. En concreto, el Comité de Derechos del Niño (órgano que la Convención instituye para vigilar su efectivo cumplimiento), ha privilegiado la universalidad del texto a un estricto control sobre las reservas, aunque sí se ha pronunciado en ocasiones sobre las reservas de carácter general, recomendando, eventualmente, a los Estados limitar el alcance de las mismas o retirarlas. En: Informe de la reunión del grupo de trabajo sobre reservas. 18. reunión de los presidentes de los órganos creados en virtud de los tratados de derechos humanos. Ginebra, 22 y 23 de junio de 2006. http://www.unhchr.ch/tbs/doc.nsf/0/ca47b554c532ddf8c12571a8002fb990/\$FILE/G0642935.doc

19 Hans-George Gadamer, en sus reflexiones sobre la hermenéutica, alude a determinados «prejuicios» o preestructuras de comprensión — precomprensiones — que iluminan el entendimiento de un texto. Según el autor, «la anticipación de sentido que guía nuestra comprensión de un texto no es un acto de la subjetividad sino que determina desde la comunidad que nos une con la tradición». Gadamer, H. G: Verdad y Método I, Ediciones Sígueme, Salamanca, 1996, p. 363. 
principios a los que se acaba de aludir. La nueva visión de la menor edad ha conllevado la mutación del centro de gravedad sobre el que pilota la protección del menor: de la tradicional «solidaridad» o «caridad» del «protector», a la autonomía, personalidad y necesidad de desarrollo del «protegido». Una filosofía fraguada en diferentes disciplinas, en especial la psicología ${ }^{20}$, que irradió también a la ciencia jurídica, y constituyó el motor de arranque de un proceso de modificación normativa en materia de protección del menor. El menor pasa de ser alguien meramente protegido o sujeto pasivo - casi un simple «objeto»- de protección, a considerarse "persona» en toda su dimensión, y como tal, titular de derechos fundamentales y del presupuesto natural de los mismos, la dignidad y el libre desarrollo de la personalidad, por más que tenga restricciones o condicionamientos al ejercicio de algunos de esos derechos. Pero para determinar el quantum de dichas restricciones, ha de aplicarse una lógica gradual y casuística, atendiendo a la edad y desarrollo evolutivo del menor y valorando las posibilidades de «autoejercicio»/«autoprotección» de sus derechos frente a la necesidad o conveniencia del «heteroejercicio»/ /heteroprotección» ${ }^{21}$ de los mismos, que se brindará de forma subsidiaria e instrumental, en virtud de sus especiales necesidades tuitivas $^{22}$. La búsqueda de este delicado equilibrio requiere una valoración del concreto grado de desarrollo alcanzado por el menor en la que han de tenerse en cuenta determinados elementos que sobrepasan el ámbito jurídico, por lo que será necesaria la colaboración interdisciplinar.

En conclusión, el menor es titular de derechos fundamentales y posee una capacidad de obrar progresiva para el ejercicio de los mismos. Si bien la mayoría de edad es una condición para el pleno ejercicio de los derechos, las limitaciones al ejercicio derivadas de la menor edad deben tener carácter restrictivo, y fundarse en la especial necesidad de protección.

Por otra parte, las obligaciones estatales derivadas de la Unión Europea en materia de protección del menor son débiles y escasas. El instrumento más relevante, la Carta Europea de los Derechos del Niño, adoptado por el Parlamento

${ }^{20}$ CraIn, W.: Theories of Development: Concepts and Applicattions, Prentice- Hall, Londres, 1980; Berk, L. : Child Development, Allyn and Bacon, Boston, 1989; SCHAFFER, H. : Making decisions about children: Psycological questions and answers, Basil Blacwell, Oxford, 1990. Citados en:

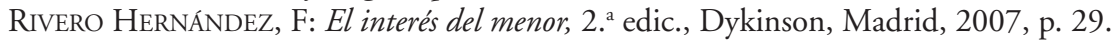
p. 64.

21 Aláez Corral, B.: Minoría de edad y derechos fundamentales, Tecnos, Madrid, 2003,

22 Benito Aláez fundamenta el reconocimiento constitucional de esta nueva concepción de la personalidad del menor en su consideración del mismo como «sujeto — igual y digno- en el proceso de comunicación social y la función determinante que en tal proceso poseen los derechos fundamentales». Idem, p. 23. 
en $1992^{23}$, carece de fuerza jurídica vinculante. Por su parte, la Carta de Derechos Fundamentales de la Unión se hace eco de varios principios fundamentales en la materia, como por ejemplo, el del interés superior del menor o su derecho participar en los asuntos que le atañen (art. 23).

Por último, al igual que España está obligada a respetar los imperativos procedentes del Derecho internacional y de la UE, ésta última también queda vinculada por los imperativos internacionalmente consensuados ${ }^{24}$, configurando así una suerte de cascada normativa de mínimos entre los tres ordenamientos.

\section{C) Disposiciones específicas}

La nota característica de las escasas disposiciones específicas, a nivel internacional y europeo, en materia de menores no acompañados solicitantes de asilo, es su debilidad normativa.

En Derecho internacional, la única disposición al efecto revestida de validez jurídica es el art. 22 de la Convención de Derechos del Niño, que impone a los estados la obligación positiva de promover activamente la protección y asistencia humanitaria del colectivo en cuestión, para que pueda disfrutar de manera efectiva de los derechos que la misma Convención, así como otros textos, le reconocen $^{25}$.

${ }^{23}$ Resolución A 3-0172/92. Este instrumento, que pretende ser una adaptación de la Convención de Derechos del Niño al contexto europeo, fue incluido también en lo que el TC denominó «estatuto jurídico indisponible de los menores de edad dentro del territorio nacional», en su STC 141/2000, de 29 de mayo. Ver nota a pie n. ${ }^{\circ} 17$.

${ }^{24}$ El artículo 63 del TCE (artículo 78 Tratado de Funcionamiento de la UE) prevé la necesaria conformidad de las medidas que se adopten en el marco del sistema europeo común de asilo con la Convención de Ginebra de 1951, su Protocolo y "otros tratados pertinentes». Este requisito se reitera en las disposiciones sobre asilo hasta ahora aprobadas, y supone una vinculación de la Unión como tal, paralela a la que posee cada Estado por su parte, a los mínimos internacionalmente consensuados. Incluida, al amparo de la rúbrica «otros tratados pertinentes», la Convención de Derechos del Niño, al menos lo dispuesto en ella sobre menores solicitantes de asilo, en su art. 22 (ver nota a pie 25).

${ }^{25}$ Artículo 22: "(1) Los Estados Partes adoptarán medidas adecuadas para lograr que el niño que trate de obtener el estatuto de refugiado o que sea considerado refugiado de conformidad con el derecho $y$ los procedimientos internacionales o internos aplicables reciba, tanto si está solo como si está acompañado de sus padres o de cualquier otra persona, la protección y la asistencia humanitaria adecuadas para el disfrute de los derechos pertinentes enunciados en la presente Convención y en otros instrumentos internacionales de derechos humanos o de carácter humanitario en que dichos Estados sean partes. (2) A tal efecto los Estados Partes cooperarán, en la forma que estimen apropiada, en todos los esfuerzos de las Naciones Unidas y demás organizaciones intergubernamentales competentes u organizaciones no gu- 
Pero, sin lugar a duda, las regulaciones más específicas en esta materia son las guías y recomendaciones del ACNUR ${ }^{26}$. Este organismo comenzó, a mediados de los ochenta, a considerar a los menores como categoría específica dentro de los refugiados, merecedora de protección especial por razón de su peculiar vulnerabilidad, situación de dependencia y desarrollo ${ }^{27}$. Si bien los instrumentos emitidos por el ACNUR no son jurídicamente vinculantes, su aplicación debe efectuarse, según la communis opinio, desde una óptica antiformalista que, sin obsesionarse por su falta de validez jurídica en sentido estricto, reconozca a estas regulaciones de soft law la eficacia jurídica e incidencia en la interpretación de las fuentes que son susceptibles de ejercer. Máxime teniendo en cuenta que, desde un punto de vista material, estas fuentes constituyen una fusión ampliada de la Convención de Ginebra y de la de Derechos del Niño, ambos textos jurídicamente vinculantes.

La dominación del «derecho blando» asoma de nuevo en el contexto de la Unión Europea, donde la regulación más específica en materia de menores solicitantes de asilo, la llamada Resolución relativa a menores no acompañados nacionales de países terceros $^{28}$, tampoco recoge normas jurídicas en sentido estricto, sino unas disposiciones de carácter finalista que describen cuál debería de ser el comportamiento de los estados en esta materia ${ }^{29}$.

En conclusión, el procedimiento nacional de asilo de menores debe respetar unos mínimos derivados del sistema internacional de protección de refugiados y

bernamentales que cooperen con las Naciones Unidas por proteger y ayudar a todo niño refugiado y localizar a sus padres o a otros miembros de su familia, a fin de obtener la información necesaria para que se reúna con su familia. En los casos en que no se pueda localizar a ninguno de los padres o miembros de la familia, se concederá al niño la misma protección que a cualquier otro niño privado permanente o temporalmente de su medio familiar, por cualquier motivo, como se dispone en la presente Convención».

${ }^{26}$ Los documentos más relevantes para el tema objeto de estudio son: Niños refugiados. Directrices sobre Protección y Cuidado; Directrices sobre Politicas y Procedimientos en la atención de menores no acompañados solicitantes de asilo; Los Niños no Acompañados en Europa. Declaración de buena práctica (elaborado conjuntamente entre ACNUR y Save the Children) y Manual de Procedimientos y Criterios para determinar la Condición de Refugiado.

27 En 1987, el Comité Ejecutivo del ACNUR condena la violencia ejercida sobre los niños, y establece que este colectivo, que sufre una mayor vulnerabilidad dentro de los refugiados, debe ser el primero en recibir protección y asistencia. En COMITÉ EJECUTIVO DEL ACNUR, Resolución n. ${ }^{\circ}$ 47, de 22 de octubre de 1987. De contenido similar: Conclusión n. ${ }^{\circ} 59$ de 13 de octubre de 1989. En los años sucesivos el Comité sigue adoptando resoluciones sobre el problema de los niños refugiados pero ninguna tan amplia como la n. ${ }^{\circ} 47$. Puede consultarse en: http://www.unhcr.ch/cgi-bin/texis/vtx/doclist?page=excom\&id=3bb1cd174\&skip=30\&list2=

${ }_{28}$ Ver nota a pie nr. 2.

29 Santolaya Machetti, P.: El derecho de asilo...op.cit, p. 166.

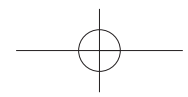


de menores de edad, así como de la normativa de la Unión. Dicho procedimiento debería adecuarse también a las regulaciones de soft law, en especial, las emitidas por el ACNUR que, como veremos, y dado su grado de especificidad, que supera al alcanzado tanto en el Derecho interno como en el internacional en la materia, a menudo serán las únicas pautas de actuación de las que disponen los poderes públicos intervinientes. La limitada operatividad jurídica de estos instrumentos genera, ya adelanto, la falta de aplicación efectiva de algunos de ellos, que permanecen en el limbo de las "buenas prácticas» en detrimento de la debida protección del derecho de asilo de este colectivo. Y es que las garantías procesales específicas que estos instrumentos prevén inciden de forma directa en el efectivo ejercicio un derecho de cariz esencialmente procesal.

\subsection{Derecho interno}

\section{A) La Constitución y el Derecho internacional}

Como se ha visto, el ordenamiento español en este tema ha alcanzado un alto grado de compromiso con los imperativos internacionales y europeos. No obstante, mientras que los mecanismos de integración y aplicación del Derecho de la Unión en el ordenamiento interno son seguros y normalizados, la integración del Derecho internacional, y sobre todo de las disposiciones de soft law, comporta una considerable dosis de incertidumbre.

Los convenios internacionales aludidos poseen una doble o triple (en lo que a protección de la menor edad se refiere) virtualidad en el Derecho interno. En primer lugar, ex art. 96.1 CE, los tratados válidamente celebrados forman parte del ordenamiento desde que son publicados oficialmente, y además están dotados de una peculiar «resistencia pasiva» $\mathrm{o}$ «mayor rigidez» ${ }^{30}$. Sin embargo, la eficacia concreta derivada de tal integración no está del todo clara.

Pero además, en virtud del art. 10.2 $\mathrm{CE}^{31}$, estos convenios, como instrumentos internacionales reguladores de derechos humanos, son canon herme-

${ }^{30}$ Deriva de la circunstancia de que no pueden ser derogados, modificados o suspendidos por una ley posterior, sino sólo «en la forma prevista en los propios tratados o de acuerdo con las normas generales de Derecho Internacional» (art. 96 CE). STC 36/1991, de 14 de febrero, FJ 5.

31 Art. 10.2: «Las normas relativas a los derechos fundamentales y a las libertades que la Constitución reconoce se interpretarán de conformidad con la Declaración Universal de Derechos Humanos y los tratados y acuerdos internacionales sobre las mismas materias ratificados por España». 
néutico de los derechos fundamentales constitucionales ${ }^{32}$, lo que en la práctica les otorga un significativo carácter integrador de los mismos ${ }^{33}$. Este «reenvío recepticio de carácter interpretativo ${ }^{34}$ que hace el art. 10.2 es igualmente aplicable, como es obvio, cuando el titular de los derechos objeto de interpretación es un menor, lo que da entrada a la Convención de Derechos del Niño y otros convenios especializados también como herramienta para la «especificación» de los derechos regulados en abstracto a la especial situación de que sea un menor quien los ejerza. Pero esta «interpretación internacionalmente adecuada» se enfrenta a un límite de la imposibilidad de creación de nuevos derechos ${ }^{35}$, límite que el TC ha relativizado en la práctica mediante el reconocimiento de nuevos contenidos a viejos derechos ${ }^{36}$.

Y por último, los tratados internacionales que velan por la protección del menor, en especial la Convención de Derechos del Niño, poseen una tercera vía adicional de entrada a nuestro ordenamiento, la recogida en el art. 39.4 CE. En virtud de dicho precepto, ubicado en el Capítulo III del Título I, «los niños gozarán de la protección prevista en los acuerdos internacionales que velan por sus

32 Alejandro Saiz Arnaiz, defiende y argumenta que debe aplicarse aquí una interpretación amplia de los términos «derechos fundamentales y libertades» del art. 10.2 CE, que incluya a todos los derechos recogidos en el Título I de la Carta Magna. Cfr. SAIZ Arnaiz, A.: La apertura constitucional al derecho internacional y europeo de los derechos humanos. El artículo 10.2 de la Constitución Española, Consejo General del Poder Judicial, Madrid, 1999, p. 66.

${ }_{33}$ Idem, p. 85. El autor repasa la jurisprudencia del TC sobre el alcance del 10.2 CE y concluye que, según el Alto Tribunal, los tratados internacionales son «instrumentos valiosos para configurar el sentido y alcance de los derechos» (STC 254/1993, de 20 de julio, FJ 6, entre otras), «contribuyen a la mejor identificación de su contenido» (STC 77/1995, de 22 de mayo, FJ 2, entre otras), y poseen una dimensión «integradora» de los mismos (STC 181/1994, de 20 de junio, FJ 2).

34 FERnÁndez TOMÁs, A. F.: «La válida celebración y la incorporación de los tratados en la jurisprudencia constitucional española», en PÉrEZ GonZÁlez, M (Coord.): Hacia un nuevo orden internacional y europeo: estudios en homenaje al profesor don Manuel Diez de Velasco, Ed. Tecnos, 1993, pp. 341-360 (p. 354).

35 SAIZ ARnaIZ, A.: La apertura constitucional...op.cit, p. 79.

36 Reconociendo expresamente la influencia del Convenio Europeo de Derechos Humanos y la jurisprudencia del TEDH, el TC ha incluido, vía artículo 10.2 CE, el derecho al juez imparcial (art.117.1 CE) en el derecho a un proceso con todas las garantías (24.2 CE), SSTC 145/1988, de 12 de julio (FJ 5) y 39/2004, de 22 de marzo (FJ 3). Asimismo, el TC ha acabado aceptando, también por influencia directa del TEDH y de la interpretación que éste hace del $\mathrm{CEDH}$, como contenido del derecho a la intimidad personal y familiar, en su vertiente de derecho a la inviolabilidad de domicilio, la protección frente a daños medioambientales que impidan o dificulten gravemente el libre desarrollo de la personalidad. STC 119/2001, de 24 de mayo (FFJJ 5 y 6). Citadas en Ripol Carulla, S.: El sistema europeo de protección de los derechos humanos y el Derecho español, ed. Atelier Internacional, Barcelona, 2007, pp. 168-175. 
derechos». La ubicación constitucional y la literalidad de este precepto le confieren un alcance distinto al del art. 10.2 CE. La ubicación constitucional da cuenta de su naturaleza de principio rector. Como tal, la primera de sus funciones es imponer «una obligación de hacer, un pactum de contrahendo, que obliga al Estado a ser parte en todos los convenios protectores de la infancia», vigentes y futuros ${ }^{37}$. Aceptado esto, el dilema ulterior sería determinar si la eficacia normativa de dichos tratados, una vez ratificados por España, es similar a la que al resto atribuye el art. $96.1 \mathrm{CE}^{38}$, o si tales instrumentos revestirían, además, la naturaleza de principios rectores, al «ocupar» el puesto del precepto que los invoca $^{39}$. Esta última es la tesis a la que implícitamente parece adherirse el TC, cuando en su jurisprudencia invoca el art. 39.4 como un mandato genérico a los poderes públicos de protección a la infancia y a continuación completa o concreta el contenido material de dicho mandato con disposiciones recogidas en tratados internacionales sobre derechos de menores, en especial, la Convención de Derechos del Niño ${ }^{40}$.

La literalidad del precepto también le otorga un alcance diverso al del art. 10.2 CE. El art. 39.4 CE no se refiere a la función hermenéutica de los tratados que invoca, sino que simplemente ordena su eficacia. La vía de entrada de los tratados en virtud de ese precepto es diferente a la que éstos y otros convenios poseen $e x$ art. 10.2 CE. No se requiere un «asidero» del que pender un precepto internacional para que éste se integre en nuestro ordenamiento, como ocurre en el art. 10.2 CE, por amplia que haya sido la interpretación de tal «asidero» ${ }^{41}$.

37 Fernández TOMÁs, A.: op.cit. p. 354.

38 Esta es la tesis mantenida por Antonio Fernández Tomás. Idem, p. 355.

39 En este sentido parece decantarse la STC 30/1991, de 14 de febrero, FJ 5, al afirmar que el 39.4 CE «opera una recepción genérica de esas normas de protección que, sin embargo, y a diferencia de lo que sucede en el caso del artículo 10.2 no incorpora el contenido propio de derecho fundamental alguno, puesto que, en general (art. 53.3 CE), los principios reconocidos en el Capítulo Tercero del Título Primero, aunque deben orientar la acción de los poderes públicos, no generan por sí mismos derechos judicialmente actuables».

40 STC 55/1994, de 24 de febrero, FJ 2. En ella, el TC se apoya en el mandato constitucional de protección de la infancia del artículo 39.4 CE para justificar un trato diferenciado del menor basado en una finalidad tuitiva, e invoca, junto a este precepto, el artículo 19 de la Convención de Derechos del Niño para concretar cómo debe ser la actitud protectora del Estado en el caso que se presenta. Utiliza dicha disposición de la Convención como uno de los parámetros para determinar la constitucionalidad del precepto legal invocado, como si de un principio rector se tratara. En la STC 71/1990, de 5 de mayo, FJ 7, el Alto Tribunal también se apoya en el artículo 39.4 CE y, en virtud del reenvío que hace éste, en concretas disposiciones de convenios internacionales, que considera "directamente aplicables», para justificar la constitucionalidad de la aplicación de un régimen limitativo de publicidad en los procesos de menores.

41 Ver nota a pie nr. 36. 
No menciona el artículo que nos ocupa ningún precepto que haya que interpretar o aplicar de manera conforme a los tratados internacionales invocados, sino que éstos entran a formar parte del ordenamiento jurídico en virtud del reenvío genérico constitucional, ocupando el mismo puesto que el precepto que a ellos remite. Probablemente, a diferencia de los textos introducidos en virtud del 10.2 CE, estos instrumentos sí pueden innovar creando nuevos derechos.

El revestimiento de los acuerdos internacionales que velen por los derechos del menor de la naturaleza de principios rectores en nuestro ordenamiento irradia consecuencias interesantes. En primer lugar, aquellos instrumentos deberán informar «la legislación positiva, la práctica judicial y la actuación de los poderes públicos» (art. 53.3 CE). Asimismo, como principios rectores, dichos acuerdos pueden servir de parámetro para que el Tribunal Constitucional lleve a cabo el control de constitucionalidad de las leyes ${ }^{42}$.

En conclusión, la apertura constitucional al Derecho internacional en materia de protección del menor es especialmente intensa. Los tratados en la materia quedan integrados en el Derecho interno mediante tres vías diversas, a saber, las previstas en los preceptos 96, 10.2 y 39.4 de la Carta Magna. Las exigencias derivadas de esta triple recepción deben plasmarse en toda actuación o norma que afecte a menores, incluidas, claro está, las relativas al procedimiento de asilo.

B) La doble dimensión de la protección constitucional del menor

La protección jurídica del menor posee en la Constitución una doble dimensión. Por una parte, una subjetiva, fundada en la dignidad y libre desarrollo de la personalidad que corresponde a todos, incluidos los menores. Partiendo de este postulado, el menor será titular de los derechos fundamentales constitucionales y, en línea con la ideología subyacente, beneficiario de una presunción de capacidad de obrar iusfundamental que sólo podrá limitarse de manera restrictiva y fundada en la concreta y razonada necesidad de protección especial ${ }^{43}$. La exposición de motivos de la Ley Orgánica de Protección Jurídica del Menor ${ }^{44}$ (en adelante, Ley del Menor) es especialmente ilustrativa en lo que se refiere a

42 LÓpez Guerra, L.: Derecho Constitucional. Vol 1. El ordenamiento constitucional. Derechos $y$ deberes de los ciudadanos, Tirant lo Blanch, Valencia, 2007, p. 445. El autor se refiere estrictamente a los principios rectores constitucionales.

43 Cfr. Aláez Corral, B.: op.cit, p. 124.

${ }^{44}$ Ley Orgánica 1/1996, de 15 de enero, de Protección Jurídica del Menor, de modificación parcial del Código Civil y de la Ley de Enjuiciamiento Civil. 
este presupuesto inspirador y hermenéutico. ${ }^{45}$ Los derechos fundamentales constitucionales se interpretarán, como se acaba de ver, de acuerdo con los tratados internacionales reguladores de derechos humanos (10.2 CE).

Pero una panorámica completa del estatuto jurídico del menor solicitante de asilo desde una perspectiva subjetiva no puede soslayar la segunda de las condiciones definitorias de este colectivo: la extranjería. Según la jurisprudencia constitucional, el legislador está legitimado ex constitutione (art. 13.1) a establecer ciertos límites sobre el ejercicio de algunos derechos fundamentales por los extranjeros, siempre que, en primer lugar, no afecten a derechos que «son imprescindibles para la garantía de la dignidad humana ${ }^{46} \mathrm{y}$, en segundo lugar, se respeten los mandatos constitucionales, tanto en lo concerniente al contenido esencial o preceptivo del derecho, como a la interpretación internacionalmente conforme impuesta por el $10.2 \mathrm{CE}^{47}$. Aunque el postulado de partida es el principio de igualdad y la prohibición de discriminación entre nacionales y extranjeros ${ }^{48}$, parece que todavía quedan parcelas no vedadas a la diferenciación en la regulación del ejercicio de determinados derechos ${ }^{49}$, diferenciación que siempre ha de dirigirse «a preservar otros derechos, bienes o intereses constitucionalmente protegidos» $\mathrm{y}$ "guardar la adecuada proporcionalidad con la finalidad perseguida ${ }^{50}$.

45 Alude tal Exposición de Motivos, por ejemplo, al «nuevo enfoque dado a la construcción del edificio de los derechos humanos de la infancia», o al «reconocimiento pleno de la titularidad de derechos en los menores de edad y de una capacidad progresiva para ejercerlos».

46 Por todas: STC 236/2007, de 7 de noviembre, FJ 3.

${ }^{47}$ Javier García Roca cree que se ha de partir de la base de que, con excepción de ciertos derechos políticos, los derechos fundamentales corresponden, ex constitutione, tanto a los nacionales como a los extranjeros, y aboga por aplicar la sensibilidad propia de los derechos fundamentales a la extranjería. Asimismo, el autor propone ciertas pautas para la mejor comprensión del concepto «contenido esencial», cuando éste atañe a los derechos fundamentales de los extranjeros. GARCÍA RocA, J.: «La titularidad constitucional e internacional de los derechos fundamentales de los extranjeros y las modulaciones legales a sus contenidos», en REvENGA SÁNCHEZ, M. (coord.): Problemas constitucionales de la inmigración: Una visión desde Italia y España (II Jornadas Italo-españolas de Justicia constitucional), Tirant Lo Blanch, Valencia, 2005, pp. 71-108, p. 78.

48 Art. 3.1 de la Ley Orgánica 4/2000, de 11 de enero, sobre derechos y libertades de los extranjeros en España y su integración social: «Como criterio interpretativo general, se entenderá que los extranjeros ejercitarán los derechos que les reconoce esta ley en condiciones de igualdad con los españoles».

49 Así, hay derecho fundamentales que admiten modulaciones a su ejercicio basadas en la condición de extranjero, como es la libertad de circulación (art. 19 CE)(STC 94/1993, de 22 de marzo); derecho a la libertad y seguridad (art.17 CE), atenuado por los ingresos en los Centros de Internamiento de Extranjeros; derecho al trabajo (art. 35 CE) (STC 107/1984, de 23 de noviembre).

50 STC 236/2007, de 7 de noviembre, FJ 4. 
Sin embargo, tratándose de menores, este tipo de diferenciación (que para los adultos no es discriminatoria) no parece posible. $Y$ es que la finalidad de protección de otros bienes o derechos constitucionales — potencialmente legítima para justificar diferenciaciones de trato respecto de extranjeros adultos- decae siempre cuando se pondera frente al principio fundamental en la materia que nos ocupa: la supremacía del interés del menor. Más abajo aludiremos a las implicaciones de este principio en la ponderación jurisdiccional de derechos. La legislación española en materia de protección de menores, muestra, con distintas pinceladas, su anuencia a esta exigencia ${ }^{51}$.

Pero la protección de la infancia también tiene en nuestro ordenamiento fuertes connotaciones objetivas. El art. 39 ha de entenderse desde el prisma de la responsabilidad que para los poderes públicos implica la fórmula jurídico-política consagrada por el constituyente, el Estado Social y Democrático de Derecho $(\text { art. 1.1 CE })^{52}$. La vertiente social del Estado exige una función promocional, de vigilancia activa del poder en pro de la dignidad y libre desarrollo de la personalidad (art. 10.1 CE), especialmente de las del menor, dada su congénita vulnerabilidad. La llamada "cláusula de transformación social» del art. 9.2 CE irradia así a todo el ordenamiento jurídico cuando encomienda a los poderes públicos la función de "promover las condiciones para que la libertad y la igualdad del individuo y de los grupos en que se integra sean reales y efectivas [y] remover los obstáculos que impidan o dificulten su plenitud ${ }^{53}$.

Estos postulados cobran su máximo sentido frente a los colectivos desfavorecidos o adolecientes de un mayor grado de vulnerabilidad, como es el caso de los menores de edad. Pero es que además, respecto a estos últimos, el TC ha definido el compromiso de los poderes públicos con mayor vehemencia y rotundidad. En la STC 141/2000, de 29 de mayo, el Alto Tribunal se apoya en el mandato del art. 39.4 CE para proclamar que, lo que denominó «estatuto jurídico indisponible del menor de edad dentro del territorio nacional», conforma-

${ }^{51}$ A modo de ejemplo, la detención en Centros de Internamiento de Inmigrantes o la expulsión son medidas admitidas para extranjeros adultos pero proscritas para menores. Asimismo, la asistencia sanitaria no admite diferencias en menores por razón de la situación administrativa, como ocurre en el caso de los adultos (en este caso, por la circunstancia de estar o no empadronados).

52 Según Encarna Carmona, «el principio de Estado social supone una reinterpretación de los presupuestos básicos del Estado de Derecho, sin renunciar a sus postulados esenciales». CARMONA CuEnCA, E.: El Estado Social de Derecho en la Constitución, Consejo Económico y Social, Madrid, 2003, p. 117.

53 ELÍAs MÉNDEZ, C.: La protección del menor inmigrante desde una perspectiva constitucional, Tirant lo Blanch, Valencia, 2002, p. 41. 
do por la Convención de Derechos del Niño, la Carta Europea de los Derechos del Niño del Parlamento Europeo y la Ley del Menor, es, «sin duda, una norma de orden público, de inexcusable observancia para todos los poderes públicos» (FJ 5). Tal calificación jurídica entraña, como destaca Francisco Rivero, una serie de consecuencias en la interpretación que ha de darse a ciertas normas, en la resolución de determinados conflictos de intereses (que afectan al menor) o en la legitimidad de determinados límites a algunos derechos y a ciertas funciones y facultades, como la patria potestad ${ }^{54}$.

\section{C) Desarrollo infraconstitucional relevante}

La regulación del asilo en nuestro ordenamiento jurídico posee escasísimas disposiciones específicas sobre refugiados menores no acompañados. La norma nuclear es la recogida en el art. 15.4 del Reglamento de Asilo, que prescribe un conjunto de pautas a seguir en los procedimientos de asilo de los menores en situación de desamparo. En lo no previsto en dicho artículo, se aplicará lo dispuesto por la Ley y el Reglamento de Asilo para el procedimiento de asilo en general ${ }^{55}$. De manera supletoria, se aplicará lo previsto para el procedimiento administrativo común ${ }^{56}$.

Dada la condición de extranjero del menor solicitante de asilo, habrá de atenderse también a lo dispuesto en la legislación de extranjería (Ley y Reglamento de Extranjería ${ }^{57}$ ) para cerrar la configuración de su régimen jurídico.

Respecto a menores en general, el instrumento principal es la Ley Orgánica de Protección Jurídica del Menor, que aúna normas que por afectar directamente a derechos fundamentales revisten la naturaleza de orgánicas, junto a disposiciones dictadas en aplicación de competencias exclusivas, como las que recaen sobre materia civil, y a normas de aplicación supletoria de la que dicten las Comunidades Autónomas en materia de "asistencia social»" ${ }^{58}$.

54 Rivero Hernández, F.: op.cit, pp. 36-37.

55 Ley 5/1984, de 26 de marzo, reguladora del derecho de asilo y de la condición de refugiado, modificada por la Ley 9/1994, de 19 de mayo y Real Decreto 203/1995, de 10 de febrero, por el que se aprueba el Reglamento de aplicación de la Ley de Asilo.

56 Ley 30/1992, del 26 de noviembre, del Régimen Jurídico de las Administraciones Públicas y del Procedimiento Administrativo Común.

57 Ley Orgánica 4/2000, de 11 de enero, sobre derechos y libertades de los extranjeros en España y su integración social y Real Decreto 2393/2004, de 30 de diciembre, por el que se aprueba el Reglamento de ejecución de la Ley Orgánica 4/2000.

58 Pérez Vera, E.: «El derecho de protección a los menores», op.cit., (p. 1316). 
Además, el carácter transversal de la temática de la «protección del menor» (en el que inciden aspectos sanitarios, educativos, migratorios, etc.) conlleva que tanto el Estado como las Comunidades Autónomas hayan adoptado leyes relevantes en la materia. Además, si bien la "protección del menor» como tal no fue catalogada como materia competencial por el constituyente ${ }^{59}$, las actuaciones en este ámbito se han subsumido en la competencia de "asistencia social» (148.1.20 . $\left.{ }^{a} \mathrm{CE}\right)$, asumida por todas las Comunidades Autónomas. De ahí el carácter polimórfico del marco jurídico de protección del menor, para cuya configuración completa ha de acudirse al desigual desarrollo normativo efectuado en cada una de las Comunidades Autónomas.

\section{ALGUNOS PRINCIPIOS}

Dice Zagrebelsky que el paso del Estado legislativo decimonónico al Estado constitucional contemporáneo supuso un cambio estructural, "genético», del Derecho, pasando de ser «derecho por reglas» a «derecho por principios», cualitativamente distinto, lo que tiene consecuencias en la jurisdicción ${ }^{60}$.

Gracias a este cambio es posible la actualización constante del ordenamiento de forma paralela a la evolución social. Los principios, además, dotan de unidad y armonía a un sistema basado en el pluralismo de ideas y repleto de reglas producto de la frenética actividad del legislador de nuestros días.

A pesar de la enorme dificultad de demostrar la existencia de los principios jurídicos, en estas líneas nos aventuraremos a considerar como integrantes de esta categoría a ciertos valores sobre los que existe consenso en materia de protección del menor. El reflejo de dichos valores en normas internacionales, europeas e internas, así como en recomendaciones emanadas de organismos especializados en la materia, abundan en la tesis de la consolidación de dichas ideas como valores ético-jurídicos socialmente aceptados, es decir, como principios.

59 En este sentido, la «materia» de protección del menor no constituye una «materia competencial», es decir, no es materia según una concepción jurídico normativa. Según Carles Viver, aunque la realidad social no permita una partición clara, esta sí puede darse en el plano jurídico. El autor resalta la consideración que hace el Tribunal Constitucional de las materias (competenciales) como conceptos jurídicos elaborados por la ciencia del Derecho mediante una reconstrucción tipológica de la realidad. Para la delimitación de las materias competenciales, el TC parte fundamentalmente de las definiciones de las materias que daba el ordenamiento jurídico en vigor en el momento de dictarse la Constitución y los Estatutos de Autonomía. Cfr. VIVER I PI-SUNYER, C.: Materias competenciales y Tribunal Constitucional, Editorial Ariel, S.A, Barcelona, 1989.

${ }^{60}$ Zagrebelsky, G.: El derecho dúctil: ley, derechos, justicia, Ed. Trotta, Madrid, 2005, p. 112. 
La inclusión de ciertos valores en la categoría de principios implicará su ulterior utilización como fundamento del Derecho y prescripciones interpretativas e integradoras de las lagunas legales ${ }^{61}$. Adicionalmente, como resalta Zagrebelsky, impondrán un posicionamiento jurídico frente a las infinitas situaciones que la realidad puede ofrecer ${ }^{62}$.

\subsection{Supremacía del interés del menor}

Es el principio nuclear en materia de protección del menor. Se ha positivado tanto a nivel internacional, en la Convención ${ }^{63}$, como de la Unión, en la Carta Europea de Derechos del Niño ${ }^{64}$ y en la Carta de Derechos Fundamentales ${ }^{65}$, así como en el ordenamiento jurídico de la mayoría de los estados occidentales, incluido el español. Aunque nuestra Constitución no lo recoge expresamente, el TC lo considera ínsito en el art. $39^{66}$, y además hay destellos a lo largo de todo su articulado de los que bien se podría inducir la existencia de dicho principio ${ }^{67}$. La Ley del Menor lo recoge de forma contundente ${ }^{68}$, y son numerosas sus manifestaciones en el ordenamiento, sobre todo en el ámbito civil ${ }^{69}$.

Según el enunciado de los instrumentos mencionados, el principio obligaría a toda institución pública o privada que tenga que adoptar una decisión sobre un menor, a tomar como consideración principal y prioritaria el mejor interés de éste.

${ }^{61}$ Margarita Beladiez alude también a la que ella denomina olvidada función de los principios jurídicos: su justiciabilidad directa, conforme a la cual es posible recurrir cualquier acto jurídico (excepto lo que posean rango legal cuando el principio no sea constitucional) que se haya dictado desconociendo el valor que el principio contiene. Beladiez Rojo, M.: Los principios jurídicos, Ed. Tecnos, Madrid, 1994, p. 115.

${ }^{62}$ Zagrebelsky, G.: op. cit., p. 118.

63 Art. 3.1: «En todas las medidas concernientes a los niños que tomen las instituciones públicas o privadas de bienestar social, los tribunales, las autoridades administrativas o los órganos legislativos, una consideración primordial a que se atenderá será el interés superior del niño».

${ }^{64}$ Art. 8.14: «Toda decisión familiar, administrativa o judicial, en lo que se refiere al niño, deberá tener por objeto prioritario la defensa y salvaguardia de sus intereses [...]».

${ }^{65}$ Art. 23.2: «En todos los actos relativos a los niños llevados a cabo por autoridades públicas o instituciones privadas, el interés superior del niño constituirá una consideración primordial».

66 STC 141/2000, de 29 de mayo, FJ 5.

${ }^{67} \mathrm{El}$ art. 20.4 CE, por ejemplo, que señala como límite a la libertad de expresión la «protección de la juventud y de la infancia».

68 Art. 2: «En la aplicación de la presente Ley primará el interés superior de los menores sobre cualquier otro interés legítimo que pudiera concurrir [...]». Art. 11.2: «Serán principios rectores de la actuación de los poderes públicos, los siguientes: a) La supremacía del interés del menor [...]».

69 A modo de ejemplo, el artículo 154 del CC: «[...] La patria potestad se ejercerá siempre en beneficio de los hijos, de acuerdo con su personalidad [...]». 
Como principio jurídico, el interés superior del menor debe servir de fundamento de las leyes, coadyuvar a su exégesis e integrar las lagunas existentes. Sin embargo, alcanza su máximo sentido cuando impone posicionamientos frente a situaciones concretas. La prescripción que contiene es clara: ante un conflicto de intereses, deberá prevalecer el del menor. Esta lógica tiene importantes implicaciones en la ponderación de derechos, tal y como se aprecia en la jurisprudencia constitucional, que en distintas situaciones ha postergado otros derechos e intereses, por muy legítimos que fueran, en favor del supremo interés del menor ${ }^{70}$. Por ejemplo, la presencia de un menor cuyos intereses están en juego hace que conflictos jurídicos tradicionalmente privados adquieran relevancia pública, al entrar en juego un mandato constitucional de protección especial.

$\mathrm{El}$ anclaje constitucional directo del principio es el art. 39, antes reseñado, y la exigencia en él contenida de protección integral al menor. Tal mandato se enmarca en el contexto del Estado social (art. 1.1 CE), y el deber implícito de brindar una protección especial a los colectivos más desfavorecidos para lograr una igualdad real y efectiva (art. 9.2). Pero la exigencia de favorecer al menor se justifica también por la falta de desarrollo integral del mismo, que demanda una especial actitud tuitiva para poder desarrollar su personalidad libremente (art. 10.1 CE). Todos estos artículos constituyen, por tanto, el fundamento constitucional del principio del interés superior del menor.

La aplicación de este principio en la práctica es complicada. A la carga de inseguridad innata a los principios jurídicos se yuxtapone en este caso la ambigüedad inherente a un concepto jurídico tan indeterminado como «interés superior del menor». La principal crítica en esta línea apunta a la hipertrofia del concepto, que en la práctica sirve para avalar las más diversas opiniones, a veces contaminadas por intereses ajenos. Determinar, caso por caso, cuál es el concreto interés del menor, dada la imposibilidad de conocer ex ante los futuros efectos de cada hipotética decisión, supone en ocasiones un ejercicio de considerable dificultad.

En este sentido, ha habido algunos intentos de orientar la aplicación del principio y minimizar su indeterminación. Se ha hablado de los componentes objetivo y subjetivo del mismo, en referencia al equilibrio que debe buscarse entre lo social y comúnmente aceptado como beneficioso para el menor y la voluntad por éste expresada, teniendo en cuenta su capacidad y grado de desarrollo. Una propuesta bien argumentada en este sentido es la de John Eekelaar y su denominado

70 SSTC 141/2000, de 29 de mayo (FJ 5), 215/1994, de 14 de julio; 260/1994, de 3 de octubre; 60/1995, de 17 de marzo; 134/1999, de 15 de julio; 71/2004, de 19 de abril. Del Tribunal Europeo de Derechos Humanos, ver: STEDH de 23 de junio de 1993, caso Hoffmann. 
«dynamic self-determinism» ${ }^{71}$. Con esta teoría el autor pretende resaltar la condición de titular de derechos del menor y evitar la subyugación que muchas veces va unida al proteccionismo. Eekelaar defiende la utilidad del principio basándose en que, al menos, obliga a introducir temas en el proceso decisorio que no tendrían por qué contemplarse de no existir aquel, es decir, exige, como mínimo, que se considere y haga referencia a los intereses del menor a la hora de adoptar medidas que le conciernen. La teoría que propone consiste en tener en cuenta dos elementos en el proceso de decidir qué es lo que más conviene al menor. En primer lugar, lo objetiva y socialmente razonable, que no siempre será claro. En segundo lugar, se ha de escuchar la opinión del menor, aunque ésta no sea vinculante. El menor debe opinar, pero no tiene por qué decidir. Lo peculiar de esta teoría es que la opinión del menor se ve como algo dinámico, mutable, que puede evolucionar a medida que lo hace el propio menor. El objetivo inmediato, el interés superior del menor, consiste en procurar al menor el espacio necesario para que desarrolle libremente su personalidad y pueda decidir una vez que sea capaz de hacerlo. El acento recae, por tanto, en la posibilidad de revisar las decisiones en vista del desarrollo de los acontecimientos y del menor.

Existen ejemplos en el ordenamiento que reflejan esta prevalencia del interés superior y cambiante del menor sobre la seguridad jurídica; como el hecho de que en Derecho de familia las resoluciones nunca puedan alcanzar el efecto de cosa juzgada material: estos procesos deben orientarse a la protección, considerada de interés general, de la infancia como colectivo vulnerable, por lo que no debe coartarse la posibilidad de modificar las medidas que se adopten ${ }^{72}$.

Sin embargo, tanto la legislación como la jurisprudencia han optado por garantizar una mínima seguridad jurídica, en ciertos aspectos esenciales para la protección del menor, cuyo cumplimiento es predicable de forma general como beneficioso para éste y por tanto merece la pena que su regulación se congele ${ }^{73}$.

${ }^{71}$ La traducción sería algo así como «autodeterminación dinámica». EEKELAAR, J.: «Interests of the Child and the Child's wishes: the role of Dynamic Self-Determination», en International Journal of Law and the Family, vol.8, 1994, pp. 42-61.

72 CABAÑAs POVEDA, C.: «Proceso especial sobre impugnación de resoluciones administrativas en materia de protección de menores", en Revista Jurídica de la Comunidad de Madrid, n. 9, enero-abril 2001, pp. 117-125 (p.123).

${ }^{73}$ Por ejemplo, en la STC 36/1991, de 14 de febrero, el Alto Tribunal declaró el carácter jurisdiccional de los procesos correctores de menores contemplados en el Decreto de 11 de junio de 1948 (ya derogado). Tal regulación se inspiraba en un modelo que consideraba irresponsables penalmente a los menores de edad, por lo que no era posible aplicarles medidas represivas que tuviesen la consideración de penas o sanciones, y no debían aplicarse, para examinar sus actos, las garantías jurídicas de otras jurisdicciones: era el juez, sin la intervención del Ministerio Fiscal ni del abogado defensor, quien debía velar por los intereses del menor y decidir las medidas a imponer, basándose en 
La cuestión de fondo es buscar un equilibrio entre la flexibilidad que debe presidir las decisiones sobre menores, para que estas se adecuen lo más posible a cada concreta situación, y la necesaria seguridad jurídica que debe existir en determinados temas.

La mejor solución pasa, en mi opinión, por congelar legislativamente (utilizando un concepto material de ley) aquellas medidas y garantías que apriorística y objetivamente redunden en beneficio del menor. Cuando una opción es claramente beneficiosa para éste, la discrecionalidad permitida debe minimizarse y ha de optarse por la seguridad jurídica, ya que la flexibilidad, en ciertos puntos, se convierte en arbitrariedad o falta de aplicación efectiva, lo que puede transformar en mera ficción los derechos o la protección debida al menor. Más abajo se aludirá a ciertas «buenas prácticas» en el procedimiento de asilo de menores cuya aplicación indudablemente redundaría en interés del menor pero que, por no poseer validez jurídica, muchas veces se quedan en el limbo de lo que «debería ser». Su falta de aplicación efectiva puede llegar a hacer ilusorio el derecho de todo menor a solicitar asilo.

Otro componente intrínseco al principio es la necesaria apertura a una colaboración multidisciplinar para llevar a cabo su aplicación. La formación de un operador jurídico no alcanza siempre a determinar, por ejemplo, el grado de desarrollo o madurez de un menor, la fiabilidad de su testimonio o las razones que le impulsan a obrar de uno u otro modo. Esta carencia obliga a que en la búsqueda del interés superior del menor se deban considerar elementos metajurídicos aportados por psicólogos, pedagogos, educadores, médicos, etc. ${ }^{74}$

\subsection{No discriminación}

Este principio está reconocido expresamente en el ordenamiento interno por la Ley del Menor ${ }^{75}$. Además puede inferirse de una interpretación sistemática de

criterios meramente paternalistas. Frente a esta supuesta flexibilidad de actuación que buscaba su justificación en la protección más adecuada e individualizada de los intereses del menor, el TC reafirma el carácter jurisdiccional de dichos procedimientos correctores y, consecuentemente, impone la aplicabilidad en los mismos de las garantías procesales constitucionales del art. 24.2 CE.

${ }^{74}$ La exposición de motivos de la Ley Orgánica de Protección Jurídica del Menor señala que en el derecho penal de menores debe primar el superior interés del menor, interés «que ha de ser valorado con criterios técnicos y no formalistas por equipos de profesionales especializados en el ámbito de las ciencias no jurídicas».

75 Art. 3: «Los menores gozarán de los derechos que les reconoce la Constitución y los Tratados Internacionales de los que España sea parte, especialmente la Convención de Derechos del Niño de Naciones Unidas y los demás derechos garantizados en el ordenamiento jurídico, sin dis 
la Constitución atendiendo, en primer lugar, a la prevalencia del interés superior del menor sobre cualquier otro bien o derecho constitucional, por muy legítimo que sea, que impide cualquier diferencia de trato entre menores. En segundo lugar, atendiendo a la cláusula del Estado social y democrático de Derecho ${ }^{76}$, de la que deriva el compromiso de los poderes públicos frente a la intrínseca vulnerabilidad del menor extranjero, cuya patente necesidad de protección «traspasa, cuando es necesario, la férrea barrera de la nacionalidad $»^{77}$.

En el Derecho internacional, es un principio de gran arraigo y generoso reconocimiento. Se contempla en la Convención de Derechos del Niño (art. $2^{78}$ ), el Pacto Internacional de Derechos Civiles y Políticos ${ }^{79}$ y el Pacto Internacional de Derechos Económicos, Sociales y Culturales ${ }^{80}$. En materia concreta de menores no acompañados, es el ACNUR quien, en sus recomendaciones, recuerda la necesidad de que prevalezca la condición de menor sobre la de extranjero $^{81}$, para eludir las diferenciaciones de trato que en base a la última condición se podrían establecer.

En el ámbito de la UE, el principio en cuestión queda plasmado en la Carta Europea de Derechos del Niño ${ }^{82}$.

criminación alguna por razón de nacimiento, nacionalidad, raza, sexo, deficiencia o enfermedad, religión, lengua, cultura, opinión o cualquier otra circunstancia personal, familiar o social».

76 Garrorena Morales destaca el valor hermenéutico de dicha cláusula. GARRORENA MORALES, A.: El Estado español como Estado social y democrático de Derecho, Tecnos, Madrid, 1992.

77 Elías MéNDEZ, C.: op.cit, p. 45.

78 Art. 2: «1. Los Estados partes respetarán los derechos enunciados en la presente Convención y asegurarán su aplicación a cada niño sujeto a su jurisdicción, sin distinción alguna, independientemente de la raza, el color, el sexo, el idioma, la religión la opinión política o de otra índole, el origen nacional, étnico o social, la posición económica, los impedimentos físicos, el nacimiento o cualquier otra condición del niño, de sus padres o de sus representantes legales. 2. Los Estados Partes tomarán todas las medidas apropiadas para garantiza que el niño se vea protegido contra toda forma de discriminación o castigo por causas de la condición, las actividades, las opiniones expresadas o las creencias de sus padres, o sus tutores o de sus familiares».

79 Art. 24.1: «Todo niño tiene derecho, sin discriminación alguna por motivos de raza, color, sexo, idioma, religión, origen nacional o social, posición económica o nacimiento, a las medidas de protección que su condición de menor requiere, tanto por parte de su familia, como de la sociedad y del Estado".

80 Art. 10.3: «Se deben adoptar medidas especiales de protección y asistencia a favor de todos los niños y adolescentes, sin discriminación alguna por razón de filiación o cualquier otra condición».

${ }^{81}$ Manual de Buenas Prácticas del ACNUR, Principio 2..$^{\circ}$ : Los niños no acompañados recibirán el mismo tratamiento y tienen los mismos derechos que los niños nacionales o residentes. Por encima de todo serán tratados como niños. Cualquier consideración sobre su migración será secundaria».

82 Art. 8.6: «Ningún niño podrá ser objeto, en el territorio de la Comunidad, de discriminación alguna por razón de nacionalidad, filiación, orientación sexual, etnia, color, sexo, lengua, 
Dada la situación de vulnerabilidad interseccional del colectivo que nos ocupa, por su condición de menores y de solicitantes de asilo, la igualdad más relevante en este ámbito es la material o de resultados. En este sentido, el ya aludido art. 22 de la Convención de Derechos del Niño demanda un plus tuitivo y promocional del Estado hacia este colectivo, para conseguir igualdad en el disfrute de derechos.

\subsection{Participación o derecho a ser oído}

Es un principio positivado en el orden internacional (Convención de Derechos del Niño ${ }^{83}$, Manual de Buenas Prácticas del ACNUR ${ }^{84}$ ), europeo (Carta Europea de Derechos del Niño ${ }^{85}$, CDFUE ${ }^{86}$ ) e interno (Ley del Menor ${ }^{87}$ y legislaciones autonómicas).

origen social, religión, creencias, estado de salud y otras circunstancias, ni por ninguna de estas causas referidas a sus padres».

83 Art. 12: «1. Los Estados Partes garantizarán al niño que esté en condiciones de formarse un juicio propio el derecho de expresar su opinión libremente en todos los asuntos que afectan al niño, teniéndose debidamente en cuenta las opiniones del niño, teniéndose debidamente en cuenta las opiniones del niño, en función de la edad y madurez del niño. 2. Con tal fin, se dará en particular al niño la oportunidad de ser escuchado en todo procedimiento judicial o administrativo que afecte al niño, ya sea directamente o por medio de un representante o de un órgano apropiado, en consonancia con las normas de procedimiento de la ley nacional».

${ }^{84}$ Principio $3 .^{\circ}$ : «Las opiniones y deseos de los niños no acompañados deberán ser tomados en cuenta cuando se trate de decisiones que les afecten. Las medidas adoptadas se encaminarán a facilitar su participación, teniendo en cuenta su edad y madurez».

${ }^{85}$ Art. 8.14: «[...] siempre que ello no implique riesgo o perjuicio alguno para el niño, éste deberá ser oído desde el momento en que su madurez y edad lo permitan en todas las decisiones que le afecten. Con objeto de ayudar a tomar una decisión a las personas competentes, el niño deberá ser oído, especialmente en todos aquellos procedimientos y decisiones que impliquen la modificación del ejercicio de la patria potestad, la determinación de la guardia y custodia, la designación de su tutor legal, su entrega en adopción o su eventual colocación en una institución familiar, educativa o con fines de reinserción social».

${ }^{86}$ Art. 23.1 «[...] Podrán expresar su opinión libremente. Ésta será tenida en cuenta en relación con los asuntos que les afecten, en función de su edad y de su madurez».

${ }^{87}$ Art. 9: «El menor tiene derecho a ser oído, tanto en el ámbito familiar como en cualquier procedimiento administrativo o judicial en que esté directamente implicado y que conduzca a una decisión que afecte a su esfera personal, familiar o social. En los procedimientos judiciales, las comparecencias del menor se realizarán de forma adecuada a su situación y al desarrollo evolutivo de éste, cuidando de preservar su intimidad. 2. Se garantizará que el menor pueda ejercitar este derecho por sí mismo o a través de la persona que designe para que le represente, cuando tenga suficiente juicio. No obstante, cuando ello no sea posible o no convenga al interés del menor, podrá 
El derecho a ser oído es una de las manifestaciones más claras de la preconcepción del menor que subyace a las regulaciones contemporáneas. La participación del mismo va inexorablemente unida a su consideración como persona autónoma y al abandono de las tradicionales posturas paternalistas basadas principalmente en la caridad para con un colectivo de personas carentes de capacidad de obrar.

Implica el principio la obligación de escuchar al menor, tanto en el ámbito familiar, como en cualquier procedimiento administrativo o judicial que le afecte. Conlleva tanto el derecho del menor a expresar su opinión en todos los asuntos que le atañan, como la obligación de tomarla en consideración de forma acorde con su desarrollo evolutivo. La ponderación de este principio exige un adecuado descenso a la realidad.

Intrínseco en la norma aparece el concepto de minoría de edad que la misma defiende: más que un status homogéneo, se trasluce una categoría gradual. La minoría no es un centro de imputación de capacidades, que de esta forma se aplicarían «en bloque» a los inmersos en dicha categoría, sino un periodo en el que la persona avanza, dinámica y progresivamente, en la consolidación de su desarrollo pleno ${ }^{88}$. En este sentido, a medida que la capacidad del menor aumente, crecerán también sus posibilidades de autoprotección y ejercicio de sus derechos y la heteroprotección/heteroejercicio de los mismos será progresivamente relegada ${ }^{89}$.

El derecho de participación no es un derecho a decidir, sino a ser escuchado. Lo que el menor opine no tiene por qué coincidir con lo que más le bene-

conocerse su opinión por medio de sus representantes legales, siempre que no sean parte interesada ni tengan intereses contrapuestos a los del menor, o a través de otras personas que por su profesión o relación de especial confianza con él puedan transmitirla objetivamente. 4. Cuando el menor solicite ser oído directamente o por medio de persona que le represente, la denegación de la audiencia será motivada y comunicada al Ministerio Fiscal y a aquéllos».

${ }^{88}$ Es posible establecer una analogía entre esta idea y la propuesta, en sede de derecho de sufragio, por Javier García Roca, según la cual la motivación de la declaración de incapacidad electoral debe ser, además de expresa y constitucionalmente adecuada, específica, esto es, referida particularmente a la privación del derecho de sufragio, atendiendo, caso por caso, al grado de discernimiento del presunto incapaz, y distinguiendo entre sufragio activo y pasivo. La declaración de incapacidad civil no debe conllevar, según el autor, de forma automática, la incapacidad electoral. La idea de fondo es la misma: la limitación de la capacidad de obrar debe interpretarse de forma restrictiva, no es un ámbito idóneo para guiarse por presunciones. GARCÍA RoCA, J.: «Declaración de incapacidad y privación del derecho de sufragio activo y pasivo», en: SERRANO GARCÍA, I. (Coord.): La protección jurídica del discapacitado, II Congreso Regional, Tirant Lo Blanch, Valencia, 2007, pp. 171-189.

89 AlaÉz Corral, B.: op.cit, p. 64. 
ficie, que deberá determinarse en virtud de su supremo interés. Ambos principios, participación e interés superior, guardan una íntima relación en la que el primero está al servicio del segundo, que prevalecería en caso de conflicto entre ambos $^{90}$.

En el ordenamiento jurídico español, este principio se configura legalmente como un deber de los poderes públicos, una obligación de escuchar al menor en cualquier procedimiento que le afecte, cuyo incumplimiento conlleva, tratándose de un procedimiento administrativo, la nulidad de las actuaciones ${ }^{91}$, y tratándose de un contencioso, la vulneración del derecho a la tutela judicial efectiva del menor ${ }^{92}$. Por otra parte, la Ley del Menor no establece (como sí hace el CC para ciertos supuestos $^{93}$ ), un límite mínimo de edad ni de madurez para el ejercicio del derecho del menor a ser escuchado ${ }^{94}$.

No obstante, para que este derecho de participación sea real y efectivo y no ilusorio, es necesario el descenso a la realidad social que antes se reclamaba, lo que exige atender a unas mínimas garantías. Por ejemplo, el menor debe contar con la información necesaria para opinar con fundamento ${ }^{95}$, las entrevistas deben realizarse en lugares agradables y no intimidatorios, y deberán intervenir en las mismas profesionales con formación específica para tratar con menores. En esta línea, el principio de especialización de todos los agentes que intervienen en el procedimiento penal de menores ${ }^{96}$, o el incipiente principio de especialización

${ }^{90}$ La prevalencia del principio del interés superior del menor sobre cualquier otro, en particular, sobre el derecho a ser oído, se manifiesta en varios preceptos normativos. A modo de ejemplo: el art. 9.2 de la Ley del Menor, hablando del derecho del menor a ser oído, matiza: «[...] cuando ello no sea posible o no convenga al interés del menor, podrá conocerse su opinión por medio de sus representantes legales [...]»; art. 8.14 de Carta Europea de Derechos del Niño: «[...] siempre que ello no implique riesgo o perjuicio alguno para el niño, éste deberá ser oído [...]».

${ }_{91}$ Sentencia de la AP de Valencia de 30 de abril de 2002 (JUR 2002/185690); STC 221/2002, de 25 de noviembre, FJ 5.

92 STC 152/2005, de 6 de junio, FJ 3; STC 221/2002, de 25 de noviembre, FJ 5.

$93 \mathrm{El}$ art. 156 establece, hablando del ejercicio de la patria potestad: «[...]En caso de desacuerdo, cualquiera de los dos podrá acudir al Juez, quien, después de oír a ambos y al hijo si tuviera suficiente juicio y, en todo caso, si fuera mayor de doce años, atribuirá sin ulterior recurso la facultad de decidir al padre o a la madre».

94 Palma Del TeSO, A.: Administraciones públicas y protección de la infancia. En especial, estudio de la tutela administrativa de los menores desamparados, INAP, Madrid, 2006, p. 119.

${ }^{95}$ Palma del Teso, A.: op. cit, p. 121.

${ }^{6}$ Disposición Final Cuarta de la Ley Orgánica de Responsabilidad Penal del Menor: «1. El Consejo General del Poder Judicial y el Ministerio de Justicia, en el ámbito de sus competencias respectivas, procederán a la formación de miembros de la carrera judicial y Fiscal especialistas en materia de menores [...]Dichos especialistas tendrán preferencia para desempeñar los correspondientes cargos en las Audiencias Provinciales y en los Juzgados y Fiscalías de menores [ ...]». 
de letrados, del que la doctrina comienza a hablar ${ }^{97}$, bien podrían extrapolarse a todo proceso, tanto de naturaleza administrativa como contenciosa, en el que este colectivo esté involucrado.

\subsection{Responsabilidad e intervención activa de los poderes públicos en la realización efectiva de los derechos del menor}

Este principio se infiere tanto del espíritu de la Convención sobre los Derechos del Niño en su conjunto, como de concretos artículos de la misma ${ }^{98}$. Dada la naturaleza de esta fuente y la magnitud económica que tal acción positiva exigida a los poderes públicos requiere, es obvio que los preceptos de la Convención deben ser entendidos como mandatos de optimización, que exigen a los estados agotar todos los recursos que estén a su alcance para cumplir lo más escrupulosamente posible con lo prescrito.

La Unión contempla el mandato de protección genérica a la infancia en la Carta de Derechos Fundamentales ${ }^{99}$ y el de protección especial a los menores no acompañados en la Carta Europea de Derechos del Niño ${ }^{100}$.

Ya se ha aludido reiteradamente al fundamento constitucional del mandato de protección de la infancia, ubicado principalmente en los artículos 39, 1.1 y 9.2 de la Carta Magna. Además, la Ley del Menor reconoce a los menores el derecho a recibir de las Administraciones Públicas «la asistencia adecuada para el efectivo disfrute de sus derechos y que se garantice su respeto" (art. 10.1). Las le-

97 Teresa Gisbert apoya la idea de Rafael Iniesta Sabater de que es posible inferir dicho principio de ciertas normas internacionales, como la Convención de Derechos del Niño (los art. 37.d y 40.2.b.III señalan la necesidad de que la asistencia y la asesoría de un menor incurso en un procedimiento judicial sean «adecuadas»), o las Reglas Mínimas para la Administración de Justicia de Menores, Reglas de Beijing, cuyo art. 22 ordena la impartición de formación específica «a todo el personal que se ocupa de casos de menores». GISBERT JORDÁ, T.: «Derecho de Defensa y Asistencia Letrada en Procedimiento de Menores", en Revista Jurídica de la Comunidad Valenciana: jurisprudencia seleccionada de la Comunidad Valenciana, n. ${ }^{\circ}$ 16, 2005, pp. 153-182 (p. 160).

98 Art. 3.2 de la Convención: «Los Estados Partes se comprometen a asegurar al niño la protección y el cuidado que sean necesarios para su bienestar... y con ese fin, tomarán todas las medidas legislativas y administrativas adecuadas». Art. 4: «Los Estados Partes adoptarán todas las medidas administrativas y de otra índole para dar efectividad a los derechos reconocidos en el presente Convenio». Véase también el art. 22, en nota a pie n. ${ }^{\circ} 25$.

99 Art. 23.1: «Los niños tienen derecho para su bienestar a la protección y a los cuidados necesarios $[\ldots] »$.

100 8.15: «Los niños abandonados, así como los niños privados definitiva o temporalmente de su medio familiar, deberán poder gozar en todo caso de una protección y una ayuda especiales». 
gislaciones autonómicas han desarrollado esta obligación positiva de los poderes públicos.

La responsabilidad pública de protección de la infancia cobra virtualidad de dos formas, susceptibles de diferenciación, pero relacionadas entre sí. En primer lugar, de manera subsidiaria a la obligación de padres y tutores de asistir y proteger a quienes de ellos dependen. Esta variante posee un carácter progresi$v^{101}$ : su aplicabilidad aumentará de manera inversamente proporcional al nivel de protección que padres y tutores brinden a los menores. En el caso de los menores no acompañados, dada su situación de desamparo, la obligación de los poderes públicos alcanza su máxima intensidad. En segundo lugar, el principio se manifiesta de forma autónoma, como deber de los poderes públicos de establecer garantías de protección de carácter general y abstracto ${ }^{102}$. En la práctica ambas modalidades a menudo se solapan y complementan en beneficio de una protección integral del menor.

La especialidad de la protección debida a los menores se agudiza cuando éstos, además, se encuentran en la excepcional situación que implica el asilo. Es ahí donde, parafraseando a Goodwin Gill, «el término «protección» alcanza su máxima significación y sentido. Protección es un concepto amplio que debe reflejar el vasto espectro de todos los derechos humanos» ${ }^{103}$. Conlleva que el Estado asuma una posición activa de búsqueda e identificación de necesidades. Supone evaluar, en el caso concreto, qué circunstancias de la vida del menor suponen una amenaza para su bienestar y su adecuado desarrollo, así como buscar soluciones duraderas, teniendo siempre en cuenta el principio del interés superior del menor. Y entraña, asimismo, preferencia de actuación: el menor no puede frenar su desarrollo hasta que la decisión con respecto a él sea adoptada.

La Ley del Menor, que desarrolla el citado mandato constitucional, señala - sin vocación taxativa - ciertas instituciones de las que el Estado se debe auxiliar para concretar el mandato de protección, a saber: la tutela administrativa (cuya regulación se halla en el art. 172 CC), la intervención activa del Ministerio Fiscal - conociendo y promoviendo las acciones oportunas, tanto ante la administración como en el ámbito jurisdiccional correspondiente ${ }^{104}$, una Adjuntía del Defensor del Pueblo que se encargue de recibir quejas provenientes de

101 Palma del Teso, A.: op. cit, p. 122.

102 Benito Aláez, sin embargo, defiende el carácter acumulativo y no subsidiario de las obligaciones de protección del Estado con respecto a las de los padres o tutores. AlÁEZ CorRAL, B.: op. cit, p. 161.

103 GOODWIN - GILl, G. S.: op. cit., p. 99.

104 Pantoja García, F.: Algunas notas y comentarios a la Ley 1/1996, de Protección Jurídica del Menor y su aplicación práctica, COLEX, Madrid, 1997, p. 46. 
menores y, los genéricamente anunciados «recursos sociales» de los que disponga la Administración.

\section{PROCEDIMIENTO: TENUE APLICACIÓN DE LOS PRINCIPIOS GENERALES}

Según el art. 15.4 del Reglamento de la Ley de Asilo,

«Los solicitantes menores de dieciocho años en situación de desamparo serán remitidos a los servicios competentes en materia de protección de menores, poniéndolo en conocimiento, asimismo, del Ministerio Fiscal. El tutor que legalmente se asigne al menor, le representará durante la tramitación del expediente. Las solicitudes de asilo se tramitarán conforme a los criterios contenidos en los convenios y recomendaciones internacionales aplicables al menor solicitante de asilo.»

Todo lo previsto en el ordenamiento jurídico español de forma específica sobre el procedimiento de asilo de menores no acompañados — por definición, excepto los ya emancipados, en situación de desamparo- se concentra en este precepto. Según el mismo, hay cuatro especificidades procesales aplicables a este colectivo, a saber: remisión de los menores a los servicios de protección, puesta en conocimiento del Misterio Fiscal, necesidad de representación legal del menor, asignada a su tutor legal, y conformidad con convenios y recomendaciones internacionales en la materia.

La parquedad del ordenamiento en el tema parece querer compensarse con el reenvío a los textos internacionales. Sin embargo, la eficacia de dicho reenvío dista mucho de estar clara. Si interpretamos el término "conformidad» del mismo modo que en el art. 10.2 $\mathrm{CE}^{105}$, es decir, como ausencia de contradicción ${ }^{106}$, entenderemos que el procedimiento deberá realizarse tal y como las normas internacionales indican. Así expresado, la vinculación parece mayor que en el art. 10.2, y creo que así es en la realidad de las cosas: a diferencia de la prescripción constitucional, que impone una interpretación de normas constitucionales conforme a normas internacionales, el art. 15.4 impone una actuación conforme con los parámetros internacionales, en ausencia de normas internas. En este caso, si los trámites del procedimiento no siguen la única regulación existente - la internacional — se vulnerará la conformidad. No hay normas internas que haya que interpretar de una u otra manera: sólo hay normas internacionales frente a unos trámites que desarrollar.

\footnotetext{
105 Ver trascripción del artículo en la nota a pie n. ${ }^{\circ} 31$.

106 SaIz Arnaiz, A.: op.cit, p. 221.
} 
No obstante, el tenor de la prescripción no es idónea para asegurar su aplicación efectiva ni la seguridad jurídica. Máxime cuando las normas reguladoras del procedimiento a las que el precepto reenvía son, en su mayoría, recomendaciones del ACNUR. Las fuentes originarias no son verdaderas normas jurídicas, y no es claro que el reenvío las haya dotado del rango reglamentario del precepto que las invoca. El resultado de esto, es que en la práctica, la actuación en esta materia parece ubicarse en el terreno del soft law, de las buenas prácticas y, en definitiva, de la no exigibilidad. Si bien los operadores jurídicos a menudo invocan las recomendaciones del ACNUR, la eficacia de dicha invocación es limitada e imprevisible. Además muchas de dichas recomendaciones no se aplican de oficio.

La referida Directiva sobre el Procedimiento de Asilo prevé también ciertas especificidades en la materia, que seguidamente se abordarán. Los miembros de la Unión debían haber transpuesto su contenido antes del 1 de diciembre de 2007, pero muchos, entre ellos España, no han cumplido todavía con dicha obligación.

A continuación se analizarán aspectos puntuales del procedimiento de asilo donde estimo puede haber fisuras de protección, abordando la regulación actual y la que creo debería preverse para esos casos, atendiendo a los criterios internacionales mencionados.

\subsection{Acceso al procedimiento de asilo}

A) (Falta de) acceso

Como se apuntaba en la introducción de este trabajo, el principal problema en materia de asilo de menores no acompañados es la falta de acceso al procedimiento. Esto se debe fundamentalmente al desconocimiento que sobre este derecho constitucional impera, no sólo entre los menores, sino también entre quienes se encargan de su acogida ${ }^{107}$. La baja cifra de menores no acompañados que llega a solicitar asilo da una imagen distorsionada del problema, empañando su

107 Human Rights Watch relata cómo en las entrevistas efectuadas en los centros de acogida de Tenerife ninguno de los menores había recibido información sobre su derecho a solicitar asilo u otra forma subsidiaria de protección, ni por parte de la policía ni del personal del centro. Incluso ninguno de los trabajadores en dicho centro demostró tener un conocimiento básico sobre asilo ni sobre otras formas subsidiaras de protección. HUMAN RIGHTS WATCH: Unwelcome responsibilities: Spain's failure to protect the rights of unaccompanied migrant children in the Canary Islands, vol.19, n. ${ }^{\circ} 4$ (D), Julio de 2007. Puede consultarse en: http://hrw.org/reports/2007/spain0707

(C) UNED. Revista de Derecho Politico

N. ${ }^{\circ}$ 74, enero-abril 2009, págs. 215-260

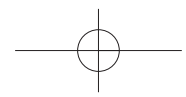


verdadera dimensión. Con seguridad, existen menores merecedores de refugio, en particular los originarios de países "exportadores» de solicitantes de asilo mayores de edad ${ }^{108}$, que nunca logran acceder a dicha protección por no saber que existe.

Los poderes públicos son responsables del cumplimiento efectivo de los derechos del menor ${ }^{109}$, para lo que deben desarrollar las medidas de protección y asistencia necesarias. En ámbito de asilo, esta obligación se traduciría en que, para que el menor ejerza su derecho al asilo de forma efectiva, el Estado (competente exclusivo en materia de asilo ex art.149.1.2 CE) y las Comunidades Autónomas (sobre las que recae la protección del menor, incluida la mayoría de las veces en la competencia de «asistencia social») deberían coordinarse para que en los servicios de protección de menores haya personal instruido en materia de asilo que, escuchando y conociendo el caso concreto de cada menor, sea capaz de informarle y asesorarle convenientemente sobre sus posibilidades de protección. Esta no es la actuación desarrollada por las autoridades españolas que, de este modo, además de faltar a su deber de protección, pueden violar también su compromiso internacional de non refoulement (art. 33 de la Convención de Ginebra), como consecuencia de la repatriación de un refugiado encubierto que desconoce que lo es.

Otra reticencia que en la práctica inhibe la presentación de solicitudes es la falsa creencia en la incompatibilidad del procedimiento de asilo con los trámites de regularización bajo la ley de extranjería. Y es que a veces los servicios de protección de menores no inician los trámites de regularización de estos porque consideran que con la tarjeta de solicitante de asilo ya están documentados, lo que provoca que muchos menores lleguen a la mayoría de edad sin haber obtenido el permiso de residencia que como menores les corresponde ${ }^{110}$, por no haberlo solicitado, en espera de la resolución de asilo. Es imprescindible, pues, que los servicios de protección de menores realicen la tramitación de la documentación de este colectivo de igual forma y con los mismos plazos que a cualquier otro menor extranjero ${ }^{111}$, porque de lo contrario estarían incurriendo en una desigualdad de trato injustificada de los menores solicitantes de asilo con respecto al resto de menores extranjeros, proscrita por el principio de no discriminación. La dejación de la obligación de regularizar al menor también puede concluir con la vulneración del principio de non refoulement.

\footnotetext{
108 Ver nota a pie número 3.

109 Art. 22 de la Convención y 10.1 de la Ley del Menor, entre otros.

110 Art. 35.4 de la Ley de Extranjería y 92.5 de su Reglamento.

111 COMISIÓN ESPAÑOLA DE AYUDA AL REFUGIADO: Informe 2007: La situación de los refugiados en España, Madrid, 2007, pp. 150-151.
} 
B) Identificación.

Previa a esta fase de detección de casos de asilo entre los menores no acompañados, está la de identificar quiénes son integrantes de este colectivo. Para ello, tanto la legislación nacional como la de la Unión prevén la posibilidad de realizar, en caso de duda sobre la edad de un solicitante de asilo (o persona inmigrante), pruebas médicas de determinación de la edad, siempre que se rodeen de las necesarias garantías ${ }^{12}$. El método debe ser respetuoso con los derechos fundamentales, y el margen de incertidumbre que acompaña al resultado ${ }^{113}$ deberá interpretarse siempre a favor del menor, en virtud de la salvaguarda de su interés prevalente y del principio de favor libertatis. No obstante, el problema en la práctica es que sólo se suele someter a este examen a quien alega ser menor, siguiendo una tácita presunción de mayoría de edad que, a pesar de que en ocasiones es lo que buscan los menores (suelen venir aconsejados erróneamente en este sentido), no es lo que más les conviene en términos de protección.

Junto a la determinación de la minoría de edad, irá la constatación de la condición de no acompañado del menor o, lo que es lo mismo, excepto en los casos de menores emancipados, de su situación de desamparo, que implicará la tutela administrativa del menor, ex art. 172 CC, y la puesta en marcha de la actuación de los servicios de protección. En este punto, el ACNUR destaca la cautela con la que se ha de actuar para determinar el tipo de relación que une al menor con los compañeros de viaje que pueda tener, que en ocasiones pueden estar camuflando bajo el disfraz de tutor o familiar su condición de traficante de menores $^{114}$.

112 Según el artículo 17.5 de la Directiva sobre el Procedimiento de Asilo para la práctica de tal reconocimiento se exige proporcionar al menor información previa sobre el método utilizado, la finalidad de la práctica y las consecuencias de los diversos resultados que la misma puede arrojar y de la negativa del menor a someterse a ella. Asimismo, dicha negativa no podrá impedir que se dicte la resolución final sobre el asilo ni será justificación suficiente para que dicha resolución sea denegatoria.// El Manual de Buenas Prácticas del ACNUR (apartado C.1.5) también recoge la exigencia de que dicho trámites no sean forzados ni irrespetuosos con la cultura del presunto menor, así como de que se le otorgue a éste el beneficio de la duda.

113 La técnica de determinación de la edad más utilizada es la denominada Greulich-Pile, basada en el análisis radiológico de los huesos de la muñeca y la mano izquierda y su comparación con unas tablas previamente elaboradas mediante estudios estadísticos que recogen el desarrollo de estos huesos a diferentes edades. El resultado emitido por estas pruebas posee, en opinión de los expertos, un margen de error de 2 años. Cfr. FERNÁNDEZ GONZÁlEZ, M. B.: El desamparo y la protección de los menores inmigrantes, Aranzadi, Cizur Menor (Navarra), 2007, pp. 162-163.

${ }^{114}$ Manual del Buenas Prácticas del ACNUR, apartados C.1.1 y C.1.2. 
C) Prohibición de detención/retención

Los solicitantes de asilo menores de edad no podrán ser objeto de ninguna modalidad de detención o retención, tal y como les ocurre a los adultos que solicitan asilo en frontera y no cumplen los requisitos de la normativa de extranjería para entrar en el territorio nacional, que están obligados a permanecer retenidos en la misma hasta que se decida sobre la admisión a trámite de su solicitud $^{115}$.

Del mismo art. 15.4 del Reglamento de Asilo se puede inferir tal prohibición. En primer lugar, de la obligación incondicional, que ese precepto impone, de poner a los menores — presumiblemente de forma inmediata — a disposición de los servicios de protección. Esta primera e inexorable pauta de actuación, que las autoridades tienen el deber de cumplir independientemente de la situación administrativa del menor, parece imposibilitar cualquier trámite intermedio, ya sea retención o sometimiento a cualquier tipo de procedimiento, entre el primer contacto del menor con las autoridades y la puesta del mismo a disposición de los servicios de protección. La lógica subyacente de protección del menor impide cualquier interpretación diversa del precepto.

La prohibición de detención de menores no acompañados puede inferirse también de la última parte del precepto, bien es verdad que con el carácter velado y desprovisto de seguridad que en este trabajo se denuncia. Así, la exigencia en él contenida de actuar de conformidad con convenios y recomendaciones internacionales, integra en nuestro ordenamiento una recomendación del ACNUR según la cual los niños refugiados, especialmente los no acompañados, no deberían ser detenidos; y bajo ninguna circunstancia podrán serlo por su condición de inmigrantes ${ }^{116}$.

115 El Defensor del Pueblo planteó un recurso de inconstitucionalidad contra el precepto de la Ley de Asilo que ordena la permanencia en el puesto fronterizo de los solicitantes de asilo en tanto en cuanto se decida sobre la admisión a trámite de su solicitud (párrafo $3 .^{\circ}$ del art. 5.7). El Tribunal Constitucional desestimó el recurso, catalogando tal permanencia en frontera de restricción a la libertad no contraria al art. 17 de la Constitución Española, por estar sujeta a los límites materiales que la misma establece como necesarios. SANTOLAYA, P.: «Sobre la constitucionalidad del procedimiento de tramitación de solicitudes de asilo en frontera tras la STC 53/02", en Revenga SÁNChEZ, M.(Coord.): Problemas Constitucionales de la Inmigración: Una visión desde Italia y España. II Jornadas Italo-españolas de Justicia Constitucional, Tirant lo Blanch, Valencia, 2005, pp. 213-225.

116 ACNUR: Guidelines on Policies and Procedures in dealing with Unaccompanied Children Seeking Asylum, Febrero 1997. www.unhcr.se/se/protect_refugees/pdf/children_world/childpolicy.pdf 
$\mathrm{Al}$ margen de las concretas regulaciones legales existentes, el propio principio del interés superior del menor aporta argumentos suficientes para tal prohibición de retención/detención. En el ámbito de asilo, las retenciones en el aeropuerto se fundamentan en una exigencia de orden público de evitar, mediante la aplicación, a modo de filtro, de la fase de inadmisión a trámite, la utilización abusiva del derecho de asilo y de procurar una gestión eficiente de los flujos migratorios. No obstante, en el caso de los menores (en especial, cuando no van acompañados), tal exigencia de orden público decae cuando frente a ella, en una ponderación, aparece el interés del menor, revestido de su supremacía frente a cualquier otro bien o derecho. La inclusión de este principio en la Convención de Derechos del Niño y en la Ley del Menor lo convierte, como se anunciaba más arriba, en «norma de orden público, de inexcusable observancia por todos los poderes públicos» ${ }^{117}$. Es evidente que lo mejor para el menor no es ser retenido en el aeropuerto y que los efectos nocivos de una detención se multiplican cuando recaen sobre un menor.

En este sentido, llama la atención la laxitud con la que el tema de la detención se regula en la Unión. La Directiva sobre el Procedimiento de Asilo prevé la posibilidad de detener a solicitantes de asilo con la única exigencia de posibilitar una revisión judicial rápida (art. 18). Sorprende la ausencia de cláusulas que protejan a los menores frente a la amplia posibilidad de detención concedida a los Estados miembros. Esta permisividad hace posible que en diversos países de la Unión se practiquen tales detenciones de menores ${ }^{118}$.

Otra peculiaridad del procedimiento de asilo de menores no acompañados, vinculada en parte a la prohibición de retención/detención, es la prohibición de someterlos a la fase de inadmisión a trámite. La imposibilidad de retener a los menores, la obligación de ponerlos de inmediato a disposición de los servicios de protección, y el hecho de que en frontera todavía no cuentan con la necesaria representación en el procedimiento, excluyen la posibilidad de someter a los menores a esa fase previa en frontera ${ }^{119}$. Pero dicha fase queda excluida en todo

117 STC $141 / 2000$, de 29 de mayo, FJ 5.

118 Un caso emblemático en este sentido es el de Italia, donde las detenciones sistemáticas de menores y la falta de garantías con las que éstas se realizan han sido denunciadas contundentemente por organizaciones como Amnistía Internacional. Véase: AMNISTÍA INTERNACIONAL: Niños y niñas invisibles: Los derechos humanos de los menores migrantes y solicitantes de asilo detenidos a su llegada a las fronteras maritimas italianas, de 23 de febrero de 2006. Disponible en: http://www.amnesty.org/es/alfresco_asset/f4f5daca-a301-11dc-8d74-6f45f39984e5/ eur300012006es.pdf. En Alemania no hay ninguna regulación especial para menores en lo que se refiere a retención de los inmigrantes. El País, 23 de mayo de 2008.

119 Apartado C. 1 del Manual de Buenas Prácticas del ACNUR: «A los niños no acompañados solicitantes de asilo nunca se les podrá negar la entrada ni tampoco serán devueltos a la fron- 
caso, no sólo en frontera, sino también en las solicitudes presentadas en territorio, ya que el carácter rápido o acelerado de tales trámites no casa bien con el interés superior del menor y la obligación de que sea escuchado de modo adecuado a sus necesidades ${ }^{120}$. Si bien este criterio suele respetarse en la práctica, no faltan excepciones en las que menores han sido retenidos en el aeropuerto y sometidos a tales trámites.

Ambas «imposibilidades», la de retención del menor no acompañado que solicita asilo y la de su sometimiento a la fase de inadmisión a trámite, constituyen una suerte de vasos comunicantes, de modo que la aplicación de una de ellas conlleva la aplicación de la segunda. No obstante, es imprescindible plasmar tales prohibiciones, ahora latentes, de forma clara y segura en la Ley o el Reglamento de Asilo.

\subsection{Representación y asistencia jurídica}

La representación y asistencia legal del menor no acompañado presenta no pocas dificultades, tanto teóricas como pragmáticas.

En primer lugar, todo menor en situación de desamparo - incluyendo, por tanto, a los no acompañados - es, por imperativo legal (art. 172 CC) y de manera automática, tutelado por la entidad pública encargada de su protección, que suele ser el organismo que cada Comunidad Autónoma designe al efecto ${ }^{121}$. Sobre dicha entidad recae la representación legal del menor, al menos en lo que al procedimiento de asilo se refiere (art. 15.4 Reglamento de Asilo).

En este contexto no parece aplicable el concepto de representación legal dominante en la doctrina, que consiste en la sustitución absoluta del representado

tera. Nunca podrán ser detenidos por motivos de inmigración. Tampoco podrán ser objeto de interrogatorios por parte de las autoridades de inmigración en la frontera».

${ }^{120}$ ECRE (European Council of Refugees and Exiles) aboga por la directa admisión de los menores no acompañados al procedimiento de asilo (eludiendo la fase de admisión a trámite), así como de eximir a dicho colectivo de cualquier procedimiento de carácter acelerado, incluida la aplicación del criterio del «tercer país seguro». ECRE: Position on refugee children, párr. 22. En la misma línea, punto C.11.1 Manual de Buenas Prácticas del ACNUR: 11.1 A los niños y jóvenes no acompañados, sin tener en cuenta su edad, nunca se les debe negar el acceso al proceso de asilo. Una vez admitidos sus procesos deben ser tramitados a través de los "procedimientos normales" y estar exentos de todos los procedimientos especiales incluidos los relacionados al «tercer país seguro», "peticiones manifiestamente infundadas" $\mathrm{y}$ "país de origen seguro" y de cualquier suspensión en la consideración de su asilo debida a venir de un "país en conflicto armado».

121 En la Comunidad Autónoma de Madrid, por ejemplo, la entidad encargada es el organismo autónomo Instituto Madrileño del Menor y la Familia. 
por el representante, sin que aquel tenga opción de intervenir en el negocio o actuación de que se trate ${ }^{122}$. La Directiva sobre el Procedimiento de Asilo, que contiene la única alusión legal a las funciones de tal figura, estipula que el representante deberá actuar en nombre del menor no acompañado o bien asistirle con respecto al examen de su solicitud (art. 17). La representación funciona aquí como complemento de la capacidad del menor, no como sustitución absoluta de su persona, en línea con la mencionada preconcepción del menor como titular de una progresiva capacidad de obrar y poseedor de un papel activo y participativo en los asuntos que le afectan ${ }^{123}$.

Por otra parte, considerar la representación como un complemento de la concreta capacidad de cada menor, excluye la posibilidad de establecer en este ámbito regulaciones que en abstracto descarten la representación de determinados menores o menores en determinadas circunstancias, por presumir que no la necesitan. Es este modelo de regulación el que recoge la Directiva sobre el Procedimiento de Asilo de la UE, al establecer como causas por las que los Estados miembros «se abstendrán» (ni siquiera dice "podrán abstenerse») de nombrar representante, el hecho de que el menor vaya a alcanzar la mayoría de edad antes de que una decisión en primera instancia sea adoptada, que pueda disponer de asesoría jurídica o de «otro consejero» gratuita, que esté o haya estado casado o que sea mayor de 16 años, "a menos que les sea imposible seguir el procedimiento sin representante» (art. 17). El precepto no es claro: excluye de la representación, por una parte, a quienes previsiblemente vayan a alcanzar la mayoría

122 De Lama Aymá, A.: La protección de los derechos de la personalidad del menor de edad, Tirant Lo Blanch, Valencia, 2006, p. 72. La autora cita a su vez, entre otros, a: DíEZ-PiCAZO, L.: La representación en el Derecho Privado, Madrid, 1979.

${ }^{123}$ En el ordenamiento jurídico existen más manifestaciones de esta filosofía: el CC, aludiendo a la representación legal que la patria potestad implica, excluye tal representación para los actos que «el hijo, de acuerdo con las Leyes y con sus condiciones de madurez, pueda realizar por sí mismo» (art. 162.2 CC). Paralelamente, la Ley de Jurisdicción Contencioso Administrativa (Ley 29/1998, de 13 de julio), en su artículo 18, reconoce a los menores de edad capacidad procesal "para la defensa de aquellos de sus derechos e intereses legítimos cuya actuación les esté permitida por el ordenamiento jurídico sin necesidad de la asistencia de la persona que ejerza la patria potestad, tutela o curatela». De hecho, en la práctica, los juzgados están permitiendo la interposición de determinados recursos, como los planteados frente a las resoluciones de repatriación, por los mismos menores no acompañados afectados, siempre que éstos tengan un cierto grado de madurez, acompañados de su abogado. No obstante, la aplicación de este criterio es, en ocasiones, perniciosa. Por ejemplo, en la Sentencia de la AN de 16 de noviembre de 2006 (Recurso n. ${ }^{\circ}$ 7/2006), se desestima un recurso contra la inadmisión de una solicitud de asilo presentada por un menor de 6 años sin representación legal pero con asistencia jurídica, aceptando la adecuación a la ley de dicha situación.

(C) UNED. Revista de Derecho Politico

N. ${ }^{7}$ 4, enero-abril 2009, págs. 215-260 
de edad antes de la adopción de la primera resolución, y por otra, a los mayores de 16 años. La primera exclusión es superflua, en vistas de la segunda. Además, las razones esgrimidas para evitar la representación soslayan el grado de madurez, desarrollo y discernimiento que el menor pueda tener. Que alguien haya estado casado o tenga 16 años no asegura su aptitud para enfrentarse en solitario a un procedimiento de tales características. Además, el papel del asesor jurídico, o de ese otro «consejero» que es suficiente para eludir su representación, no es el mismo que el del representante, es decir, proporcionar asistencia jurídica no entraña el apoyo integral que el representante debería desempeñar (información sobre el procedimiento, ayuda en la búsqueda de pruebas, en la exposición de los hechos, tomar decisiones durante el procedimiento o ayudar al menor a que las tome, etc.). La negación en abstracto y a priori del respaldo de la representación a determinados menores, sin atender a su capacidad real de desenvolvimiento, puede tener consecuencias nocivas para ellos, por prescindir de la debida protección.

Otro punto cuanto menos polémico en la regulación de este tema es que la misma administración que asume la tutela legal del menor sea también su representante. Además, aunque el organismo que asume la representación pertenezca a la Comunidad Autónoma y el órgano que decide sobre asilo (Oficina de Asilo y Refugio) se integra en la organización estatal, no parece lo más adecuado que ambos (representante y entidad que decide) pertenezcan a la Administración pública. De hecho, en materia de extranjería, y en lo que atañe a procedimientos de repatriación de menores, en ocasiones se procede al nombramiento de un defensor judicial para evitar conflictos de intereses entre el menor y su representante legal (art. 299 CC). Es verdad que en este último caso, es el mismo organismo autonómico que asume la representación y tutela el que en ocasiones solicita la repatriación, por lo que el conflicto de intereses es más evidente, no obstante, ambos (asilo y repatriación en ámbito de extranjería) son procedimientos frente a la Administración en los que se resuelve sobre la permanencia del menor y que pueden concluir- de manera más o menos mediata - con el retorno a su país de origen. En estos casos, la representación del menor debería ser externa y absolutamente independiente de la Administración, tal y como defiende el Defensor del Pueblo en su informe «Asistencia jurídica de los extranjeros en España» (2005) ${ }^{124}$, según el cual dicha representación externa sería

${ }^{124}$ El Defensor del Pueblo aboga por que se nombre un representante legal externo o un letrado que sustituya al menor no acompañado en los procedimientos administrativos o judiciales que mantenga frente a la Administración y en los que se resuelva sobre la permanencia del menor en España o el retorno a su país de origen. http://www.defensordelpueblo.es/informes2.asp 
compatible con la deseable — e inexistente en la actualidad — presencia del Ministerio Fiscal en dichos procedimientos administrativos ${ }^{125}$.

En la misma línea, el Comité de Derechos del Niño de Naciones Unidas recomienda a los estados que designen un tutor o asesor a quien se deberá consultar e informar de toda medida que la administración adopte en relación con el menor. Dicha función, aclara el Comité, no podrá ser nunca desempeñada por la administración que ejerza la tutela, ya que sus intereses pueden colisionar con los del menor ${ }^{126}$.

Aunque estas iniciativas son satisfactorias en cuanto que ponen de relieve la necesaria independencia que debe tener el representante del menor, no destacan las diferentes funciones del representante y del asesor jurídico, que impide que la intervención de uno de los dos exima la presencia del otro. Como se ha apuntado, ambas figuras cumplen funciones distintas: el menor debería contar con asesoría jurídica siempre, en todo procedimiento administrativo o judicial frente a la Administración y, adicionalmente, con un representante legal externo a —independiente de - la Administración que actué en su nombre o le asista en la medida que su desarrollo evolutivo demande.

El tema de la asesoría jurídica a menores no acompañados adolece, en la actualidad, de diversas lagunas reglamentarias y burocráticas que implican ineficiencias en la práctica cotidiana. Tales deficiencias, en parte atribuidas hasta ahora al carácter incipiente del fenómeno, no son ya tan fácilmente justificables. Es necesario que se extiendan y sistematicen protocolos de actuación entre los Colegios de Abogados, que se imparta formación específica y que las administraciones lleguen a acuerdos con los Colegios de Abogados para que el imprescindible servicio de la asistencia jurídica a este colectivo de se satisfaga con normalidad ${ }^{127}$.

125 Palma del Teso, A.: op. cit, p. 346.

126 Este Comité es el órgano que la Convención sobre Derechos del Niño establece para supervisar su cumplimiento en los Estados parte. COMITÉ DE DERECHOS DEL NIÑO, Observación General n. ${ }^{\circ}$ 6, de 1 de septiembre de 2005, sobre «Trato de los menores no acompañados y separados de su familia fuera de su país de origen» (CRC/GC/2005/6).

127 En 2007 se firmó en Cantabria un convenio entre la Delegación de Gobierno y el Colegio de Abogados para proporcionar a los menores no acompañados asistencia jurídica de letrados adscritos al turno de extranjería de dicho Colegio. En el polo opuesto se encuentra Aragón, donde no hay presencia de letrado en ningún procedimiento de repatriación amparándose en la falta de exigencia legal expresa de tal requisito. Mencionado en: LÓPEZ AzCONA, A.: «El tratamiento de los menores extranjeros no acompañados en derecho español», en Revista de Derecho Migratorio y Extranjería, Ed. Lex Nova, n. ${ }^{\circ}$ 17, Marzo 2008, pp. 103-136 (p. 116). 


\subsection{Audiencia del menor}

La fase de audiencia del menor en este procedimiento es la manifestación concreta, en sede de asilo, del principio general de participación o derecho a ser oído del menor. Como se acaba de ver, en el procedimiento de asilo este derecho puede ser ejercido por medio de un representante, pero nos centraremos ahora en las comparecencias del menor en persona.

En el procedimiento de asilo el menor tiene derecho a hablar y las autoridades obligación de escucharle. En este contexto, el derecho de audiencia del menor es una exigencia que deriva en primer lugar, como se ha apuntado, del principio de participación del menor. No obstante, dicha exigencia también se podría inferir del contenido esencial del derecho de asilo, ya que el ejercicio de éste quedaría desnaturalizado en ausencia de dicho trámite.

Que esta facultad del menor, de naturaleza procesal, posea entidad real o ficticia, depende completamente de las garantías de las que se rodee. Esto es así en cualquier procedimiento administrativo o judicial, sin embargo, cuando se trata del procedimiento de asilo, dada la delicada naturaleza que en general posee aquello que el menor «tiene que decir», y las nefastas consecuencias que podrían derivarse de no decirlo, las garantías específicas cobran su máximo sentido.

En primer lugar, es imprescindible que quien se encargue de entrevistar al menor posea una formación adecuada, tanto en asilo como en protección de menores; que esté profesionalmente cualificado para interactuar con ellos ${ }^{128}$. En este sentido, es plenamente aplicable aquí lo dicho más arriba sobre la conveniencia de extrapolar a todo procedimiento administrativo, en especial, al de asilo, el principio de especialización de los agentes interventores en procesos de menores.

Es muy conveniente, además, que el entrevistador sea cercano a la cultura del solicitante, ya que así podrá, además de empatizar mejor con él, interpretar el relato a la luz de los cánones socio-culturales adecuados, que en ocasiones son muy relevantes para un correcto entendimiento de los hechos.

128 Art. 17 de Directiva sobre Procedimiento de Asilo: «Los Estados miembros garantizarán: a) que cuando se entreviste a un menor no acompañado sobre su solicitud de asilo [...] celebre la audiencia una persona que tenga los conocimientos necesarios sobre las necesidades especiales de los menores [...]». En la misma línea: art. 19.4 de Directiva sobre normas mínimas para la acogida de los solicitantes de asilo y art. 4.5 de Resolución sobre menores no acompañados nacionales de países terceros.//Punto B.9. de Manual de Buenas Prácticas del ACNUR: «Formación de profesionales: Aquellos que trabajen con niños no acompañados deben recibir preparación específica sobre las necesidades del niño no acompañado. La policía de aduana e inmigración debe formarse en el trato adecuado a la infancia». 
Asimismo, debería ser obligatorio disponer de un amplio equipo de intérpretes al servicio de las entrevistas de menores, de manera que cada solicitante pudiera expresarse en su propia lengua y evitar así las peligrosas dificultades de comprensión en ambos sentidos que pueden derivar, como mínimo, en una incomodidad para el menor que limite su capacidad de rememorar, expresar y comprender, y como máximo en un error fatal que impida ver el fondo del caso y conduzca a una decisión desfavorable ${ }^{129}$.

El menor tiene derecho a ser escuchado, no sólo a ser oído. Es decir, la escucha debe ser activa, atenta, proclive al diálogo. El entrevistador debe ser consciente de que, además de información sobre si el solicitante merece o no el estatuto de refugiado, el testimonio del menor constituye el componente subjetivo de su superior interés.

Debe ser obligatorio también que quien entreviste al menor le realice, de modo preliminar, una composición de lugar: que le informe, de manera apropiada a su edad y desarrollo evolutivo, sobre el procedimiento de asilo, la razón y la finalidad de su intervención, las posibles consecuencias, la garantía de confidencialidad, etc. La incertidumbre provoca ansiedad innecesaria ${ }^{130}$.

Las autoridades deberían, además, responsabilizarse de que el lugar donde se realiza la entrevista sea agradable, íntimo y no intimidatorio.

La tramitación de las solicitudes de asilo de menores tiene, en virtud de las recomendaciones al efecto, carácter preferente ${ }^{131}$. Pero es fundamental no confundir preferencia con rapidez. Un menor no debe ser sometido a procedimientos de carácter acelerado, ya que muchas veces necesita tiempo para superar los posibles traumas y bloqueos, ser capaz de rememorar y sentir la suficiente confianza con su representante, abogado y/o entrevistador como para, finalmente, hablar. Es necesario actuar de manera antiformalista en este ámbito, no prefijar estrictos requisitos temporales ni someter al menor a tediosas exigencias burocráticas. El máximo criterio debe ser actuar en beneficio del concreto interés del menor. No obstante, hay que tener presente que la tramitación de estos expedientes debe ser prioritaria, es decir, el procedimiento puede extenderse por las específicas necesidades del menor, pero no por la ineficiencia o saturación de

${ }^{129}$ Manual de Buenas Prácticas del ACNUR Punto B.5 «Interpretación: Deberán facilitarse a los niños no acompañados intérpretes que hablen su primera lengua cuando sean entrevistados o necesiten acceder a servicios».

130 ACNUR: Niños Refugiados. Directrices sobre Protección y Cuidado, op. cit, p. 64.

131 BlANES GÓMEZ, E.: «Nuevos retos que plantean los menores extranjeros a la Administración General del Estado», en LÁZARO GONZÁlez, I. E y Culebras LlanA, I. P., pp. 93-110, p. 104. 
la Administración, que deberá dar preferencia a estos $\operatorname{casos}^{132}$. Una vez que la Administración cuente con la información suficiente, la resolución deberá ser rápida $^{133}$.

El factor tiempo también tendría que jugar a favor del menor en el transcurso de las entrevistas, que deberían abordarse con la flexibilidad suficiente como para ofrecer las pausas que sean necesarias para que el menor descanse, interrumpir la sesión si el estado de ánimo del mismo lo requiere, etc.

Las garantías que rodean el adecuado ejercicio del derecho a ser oído del menor deben tener un reflejo legislativo expreso que impida que su aplicación efectiva dependa de la voluntad de los agentes que intervengan en el procedimiento. La eficacia del derecho de asilo del menor depende en gran medida del cumplimiento de estos requisitos.

\subsection{Valoración y resolución}

Según el ACNUR, la determinación del estatuto de refugiado de un menor no acompañado es más complicada que la de un adulto y requiere especial atención ${ }^{134}$. Ante el silencio de nuestro ordenamiento jurídico sobre cómo abordar tal dificultad y hacer efectiva la debida especial atención, hemos de obedecer al reenvío del art. 15.4 del Reglamento de Asilo y acudir a los convenios y recomendaciones internacionales al efecto.

Conforme a dichos textos, la primera pauta para la valoración y resolución de estas solicitudes es la necesidad de contar con el informe de un experto en mentalidad infantil ${ }^{135}$, en el que, a la luz de ciertos factores, como la edad del menor y sus antecedentes personales, familiares y culturales, se valore su grado de desarrollo evolutivo, tanto en el momento en que se produce la solicitud como en el que acontecieron los hechos que la motivaron, así como su capacidad para entender, rememorar y comunicar experiencias. Este requisito debería ser exigido expresamente en la regulación interna del asilo, ya sea en la ley o en el regla-

${ }^{132}$ Manual de buenas Prácticas del ACNUR, punto B.11: «Plazos: Todas las decisiones que afecten a los niños no acompañados se tomarán en el plazo de tiempo acorde con la situación»// En el mismo sentido, párr. 8.1 de la Guía ACNUR.

133 ACNUR: Niños Refugiados. Directrices sobre Protección y Cuidado, op. cit, p. 63: «Mantener a los niños pendientes de una decisión en cuanto a su estatuto, su seguridad y su futuro, puede ser perjudicial para ellos».

${ }^{134}$ ACNUR: Niños Refugiados. Directrices sobre Protección y Cuidado, op. cit, p. 62.

135 Párr. 214 de Manual de Procedimientos del ACNUR// ACNUR: Niños Refugiados. Directrices sobre Protección y Cuidado, op. cit, p. 63. 
mento, ya que se trata de una medida que jugaría objetivamente, y en todo caso, a favor del interés del menor.

Este informe será el principal criterio a seguir para asignar un mayor o menor peso al elemento subjetivo del asilo con respecto al objetivo, teniendo siempre en cuenta que dicha ponderación se hará siempre de manera gradual. Así, atendiendo a supuestos extremos e ilustrativos, en caso de que el informe pericial determine que el menor tiene plena madurez y discernimiento, se concederá una valoración a su testimonio equivalente a la de cualquier adulto solicitante de asilo. Por el contrario, si el experto determina que el menor carece de suficiente juicio dado el incipiente grado de desarrollo o su corta edad, se deberá privilegiar en la ponderación la consideración de circunstancias objetivas, tales como las características del grupo con el que viajaba el niño, la situación de su país de origen, la de otros miembros de su familia, etc. ${ }^{136}$ Entre ambos supuestos extremos, hay una amplia graduación de desarrollos evolutivos donde la ponderación deberá ser más minuciosa. Habrá de tomarse en cuenta, adicionalmente, que es posible que los conocimientos del menor sobre las condiciones de su país de origen sean limitados ${ }^{137}$.

Por otro lado, en los procedimientos de asilo de menores no acompañados se agudiza la dificultad, generalmente presente también en las solicitudes presentadas por adultos, de constatar que el temor expresado es "fundado». Es bien sabido que en asilo, dada la especialidad del ámbito, la legislación no exige pruebas plenas de los hechos alegados, sino que es suficiente con acreditar indicios razonables de su verosimilitud. Sin embargo, tal acreditación se puede convertir, cuando atañe a menores no acompañados, en una especie de probatio diabolica, dada la falta de plena comprehensión y consecuente asimilación y exposición de los acontecimientos que puede conllevar un grado no absoluto de desarrollo evolutivo. Por esta razón, el ACNUR, así como otras organizaciones especializadas $^{138}$ y ciertos autores ${ }^{139}$, recomiendan que se realice en estos casos una «apli-

136 ACNUR: Niños Refugiados. Directrices sobre Protección...op. cit, p. 64.

137 Punto C.11.6 de Manual de Buenas Prácticas del ACNUR.

138 Por ejemplo, las organizaciones integradoras del «Programa Europeo para Niños Separados», como se puede comprobar en el artículo: SUTTON, D. y SMITH, T.: «Is Europe failing separated children?», en Forced Migration Review, n. ${ }^{\circ} 23$, mayo 2005. http://www.fmreview.org/FMRpdfs/FMR23/FMR23full.pdf

139 Tal recomendación supondría la especificación, para los menores no acompañados, del principio «in dubio pro refugiado», invocado por el Profesor MARIÑo MENÉNDEZ sobre la base de que «el estatuto de refugiado es una institución de Derecho Internacional Humanitario que requiere, por tanto, una interpretación realizada con "espiritu humanitario». MARIÑO MENÉNDEZ, F.: «El concepto de refugiado en un contexto del Derecho Internacional General», en R.E.D.I, vol. 35, pp. 340-387.

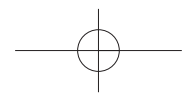


cación liberal del beneficio de la duda ${ }^{140}$, propuesta que podría desembocar en la instauración en éste ámbito - solicitudes de asilo de menores no acompañados- de la regla de la inversión de la carga de la prueba o, en este caso, de la inversión de la carga de los indicios razonables, aplicando analógicamente lo previsto por el ordenamiento para otros supuestos en los que la acreditación de lo alegado conlleva una tarea desproporcionadamente dificultosa para el actor. Y es que en este caso, además de que en ocasiones la constatación de indicios suficientes puede ser imposible de lograr atendiendo al desarrollo, discernimiento y conocimientos del menor, la evocación minuciosa y cuestionada de su testimonio puede ser perjudicial para su desarrollo.

En cuanto a la resolución de la solicitud, la Directiva de Procedimiento de Asilo (art.17) obliga a que sea un funcionario "con los conocimientos necesarios sobre las necesidades especiales de los menores» quien la prepare.

La ley tampoco prevé especificidades en cuanto a los criterios para resolver solicitudes de asilo de menores no acompañados, por lo que las posibles decisiones son, al igual que para los adultos, la concesión del asilo, la denegación del mismo o la autorización de residencia en el país por razones humanitarias. No obstante, en virtud de la remisión legal a los convenios y recomendaciones internacionales del art. 15.4 del Reglamento de Asilo, así como del mandato legal de interpretación evolutiva de las normas (art. 3 CC), las autoridades deberán dar a las disposiciones de la Convención de Ginebra y de su Protocolo una interpretación sensible a la necesidad de protección específica de los menores, armoniosa con el contexto y la realidad social a la que deben de aplicarse. Así lo ha pedido el Comité de Derechos del Niño ${ }^{141}$, abogando por desarrollar y estrechar lazos entre el sistema de protección de los refugiados con el derecho internacional de los derechos humanos. La inmersión de la protección de la infancia en el sistema de asilo implica tener en cuenta lo que el Comité califica de «formas específicas de persecución infantil», tales como el reclutamiento militar de menores, el tráfico, la explotación sexual o la mutilación sexual femenina que, siempre que estén vinculadas a uno de los motivos de persecución contemplados en la Convención de Ginebra, harán merecer al solicitante el estatuto de refugiado. Esta tendencia parece respaldada por algunas sentencias en nuestro ordenamiento, que auspician una interpretación

${ }_{140}$ Manual de Procedimientos del ACNUR, op.cit, párr. 219.

141 COMITÉ DE NACIONES UNIDAS PARA LOS DERECHOS DEL NIÑO, Comentario General n. ${ }^{\circ}$ 6, párr. 74. Disponible en inglés en: http://www.unhchr.ch/tbs/doc.nsf/ 898586b1dc7b4043c1256a450044f331/532769d21fcd8302c1257020002b65d9/\$FILE/G05438 05.pdf 
amplia de la Convención de Ginebra para adaptarla a las necesidades especiales de protección de los menores ${ }^{142}$.

Por último, el Manual de Buenas Prácticas del ACNUR (punto C.12) establece que la solución que se adopte debe inspirarse en el interés superior del menor. En este punto emerge la cuestión de la potencial contradicción entre el seguimiento del interés superior del menor y la correcta aplicación del sistema de protección instaurado en materia de asilo. Es decir, en la práctica se dan situaciones en las que el menor no cumple los requisitos consagrados en la legislación de asilo para que se le conceda el estatuto de refugiado, ni tampoco se adapta a los criterios aplicados para otorgar una autorización de residencia por motivos excepcionales, pero su especial necesidad de protección implicaría que lo mejor para él sería permanecer en España y ser beneficiario de un régimen de protección. En este caso, la vía que se utiliza en ocasiones para cohonestar las exigencias derivadas del principio del interés superior del menor y las derivadas de la correcta aplicación de la legislación en materia de asilo, es la concesión de la protección subsidiaria o residencia por motivos humanitarios con una flexibilidad mayor de lo habitual, en atención, por ejemplo, al perjuicio potencial por traumas psicológicos que la repatriación del menor puede conllevar.

\section{CONCLUSIONES}

1. La vulnerabilidad congénita y falta de desarrollo pleno del menor, unida a la traumática situación de refugio, sitúan al colectivo de los solicitantes de asilo menores de edad no acompañados en clara desventaja con respecto al resto, tanto para acceder al procedimiento de asilo, como para actuar idóneamente en el transcurso del mismo, dada su elevada complejidad. La inclusión en dicho procedimiento de ciertas garantías procesales sensibles con la especial necesidad de protección del menor se presenta así como requisito imprescindible para que este colectivo pueda gozar de forma efectiva de la protección material que conlleva el derecho de asilo.

${ }^{142}$ A modo de ejemplo, la Sentencia de la Audiencia Nacional de 12 de noviembre de 2001 (Recurso 691/2001), estima un recurso contra una denegación de asilo, reconociendo el reclutamiento militar de un menor de edad no como una forma específica de persecución, sino como un motivo de persecución en sí mismo, que implica la concesión del estatuto de refugiado a quien acredite padecerlo. Para llegar a esta conclusión se apoya en la necesidad de interpretar la Convención de Ginebra a la luz de la Convención de Derechos de Niño. 
2. La regulación vigente en España y los nuevos imperativos (todavía no traspuestos) que marca la Unión Europea en esta materia contemplan muy contadas especificidades, en modo alguno suficientes. En nuestro país, tal deficiencia intenta compensarse con una orden de tramitación del procedimiento de asilo de menores de manera conforme con los convenios y recomendaciones internacionales (art. 15.4 del Reglamento de Asilo), coherente con el reenvío genérico que el art. 39.4 CE realiza a los convenios internacionales para efectuar la protección del menor. No obstante, la indeterminación teórica de la posición y eficacia de los convenios, principios y, sobre todo, las recomendaciones internacionales en nuestro ordenamiento, hacen que tales regulaciones tengan una debilitada aplicación efectiva.

3. Existen principios internacionales en materia de protección del menor que se han consagrado también en el orden interno, en especial, el principio del interés superior del menor. Este tipo de fuente permite la flexibilidad necesaria para brindar una protección especial y ajustada al desarrollo evolutivo y circunstancias de cada menor, imponiendo posicionamientos frente a las infinitas situaciones de peligro para el menor que se pueden presentar, imposibles de etiquetar en supuestos de hecho de reglas jurídicas tradicionales.

4. Si bien es imposible —e indeseable - regular positivamente todas y cada una de las situaciones que la realidad puede presentar en materia de menores, sí existen normas y medidas concretas de las que se puede predicar, objetivamente y en abstracto, que juegan siempre en beneficio del menor. Por ejemplo, el hecho de que se procure información, tanto a los menores como a quienes se encargan de su acogida, de las posibilidades de protección a las que pueden aspirar, incluido el asilo, claramente juega en interés del menor. Así como que su representante sea independiente y externo a la administración o que no se le someta (al menor) a la fase de inadmisión a trámite y que su derecho a ser oído se rodee de las debidas garantías. O que se valore su solicitud considerando el informe que un experto realice sobre su grado de desarrollo.

5. Es necesario, para lograr una protección real y efectiva del derecho de asilo de este colectivo tan vulnerable, positivar dichas normas, incluirlas en la Ley o el Reglamento de Asilo, para conseguir su aplicación efectiva y un mayor grado de seguridad jurídica. La congelación de dichas normas y protocolos de actuación asentaría con certeza en nuestro ordenamiento lo prescrito por los convenios y recomendaciones internacionales al efecto, y sería reflejo de los principios generales aludidos. Es preciso en- 
contrar un equilibrio entre la flexibilidad que siempre ha de estar presente en las decisiones que afecten a menores y la seguridad jurídica puesta al servicio de la aplicación efectiva de normas de protección del menor.

6. Dada la naturaleza esencialmente procesal, más que sustantiva, del derecho de asilo, la aplicación efectiva de las garantías formales es imprescindible para el disfrute real y no ilusorio del derecho. Y España se ha comprometido a procurar al menor la protección necesaria para el disfrute efectivo de sus derechos (art. 22 de la Convención de Derechos del Niño).

Title

THE RIGHT TO THE ASYLUM OF NOT ACCOMPANIED MINOR: A PROPOSAL OF SURER REGULATION

\section{Summary}

1. - INTRODUCTION. 2. - SOURCES: 2.1: The relevance of the supranational norms. A) Right of asylum. B) Protection of the minor. C) Specific dispositions. 2.2. National Law. A) The Constitution and the Internacional Law. B) The double dimension of the constitutional protection of the minor. C) Important infraconstitutional development 3. - SOME PRINCIPLES: 3.1. Supremacy of the interest of the minor. 3.2. Nondiscrimination. 3.3. Participation or right to be heard. 3.4. Responsibility and active intervention of the powers public in the effective accomplishment of the rights of the minor. 4. - PROCEDURE: tenuous application of the general principles: 4.1. Access to the asylum procedure: A) (Lack of) access. B) Identification. C) Prohibition of halting/retention. 4.2. Representation and legal attendance. 4.3. Hearing of the minor. 4.4. Valuation and resolution of the asylum request. 5. - CONCLUSIONS.

\section{Resumen}

En los últimos años ha aumentado significativamente el número de extranjeros menores no acompañados que entran a España de manera clandestina. Sin embargo, estos potenciales solicitantes de asilo nunca llegan a disfrutar de la protección que legal y constitucionalmente les corresponde, al no estar bajo la tutela de sus padres o tutores. En el trabajo se identifican, en primer lugar, los preceptos de Derecho internacional, europeo e interno que, bien por regular la protección especial del menor, bien por atender a la condición de solicitante de asilo o de extranjero, deberían aplicarse en el procedimiento de asilo de menores 
no acompañados. En segundo lugar, la autora analiza los principios generales del Derecho derivados de las fuentes jurídicas mencionadas. Finalmente, se examinan ciertos aspectos del procedimiento de asilo de menores que puedan requerir, a la luz de las regulaciones y principios analizados, un tratamiento específico, determinando si tal tratamiento se refleja en la ley y/o en la práctica administrativa y, en caso negativo, si sería conveniente regularlo.

\section{Abstract}

In the last years it has increased significantly the number of not accompanied minors foreigners than they enter Spain of clandestine way. Nevertheless, these potential applicants of asylum never get to enjoy the protection that legal and constitutionally corresponds to them, when not being under the trusteeship of their parents or tutors. In this work are identified, in the first place, the rules of international, European and national Law that, either by regulating the special protection of the minor, or to take care of the condition of foreigner or asylum applicant, would have to be applied in the procedure of asylum of minors nonaccompanied. Secondly, the author analyzes the general principles of the Law derived from the mentioned legal sources. Finally, certain aspects of the procedure of asylum of minors who can require, to the light of the regulations and analyzed principles, a specific treatment are examined, determining if such treatment is reflected in the law and/or the administrative practice and, in negative case, if would be advisable to regulate the treatment.

\section{Palabras clave}

Derecho de asilo, Protección de menores

\section{Key words}

Right to asylum, Protection of the minor 